\title{
A molecular-level approach for characterizing water-insoluble components of ambient organic aerosol particulates using ultrahigh-resolution mass spectrometry
}

\author{
A. S. Willoughby, A. S. Wozniak, and P. G. Hatcher \\ Department of Chemistry \& Biochemistry, Old Dominion University, Norfolk, VA 23529, USA \\ Correspondence to: P. G. Hatcher (phatcher@odu.edu) \\ Received: 2 April 2014 - Published in Atmos. Chem. Phys. Discuss.: 24 April 2014 \\ Revised: 23 August 2014 - Accepted: 25 August 2014 - Published: 30 September 2014
}

\begin{abstract}
The chemical composition of organic aerosols in the atmosphere is strongly influenced by human emissions. The effect these have on the environment, human health, and climate change is determined by the molecular nature of these chemical species. The complexity of organic aerosol samples limits the ability to study the chemical composition, and therefore the associated properties and the impacts they have. Many studies have addressed the watersoluble fraction of organic aerosols and have had much success in identifying specific molecular formulas for thousands of compounds present. However, little attention is given to the water-insoluble portion, which can contain most of the fossil material that is emitted through human activity. Here we compare the organic aerosols present in water extracts and organic solvent extracts (pyridine and acetonitrile) of an ambient aerosol sample collected in a rural location that is impacted by natural and anthropogenic emission sources. A semiquantitative method was developed using proton nuclear magnetic resonance spectroscopy to determine that the amount of organic matter extracted by pyridine is comparable to that of water. Electrospray ionization Fourier transform ion cyclotron resonance mass spectra show that pyridine extracts a molecularly unique fraction of organic matter compared to water or acetonitrile, which extract chemically similar organic matter components. The molecular formulas unique to pyridine were less polar, more aliphatic, and reveal formulas containing sulfur to be an important component of insoluble aerosol organic matter.
\end{abstract}

\section{Introduction}

The introduction and improvement of advanced spectroscopic methods has provided a wealth of new chemical information regarding organic aerosols in the last few decades. Establishing the chemical identity of the individual components that make up organic aerosols has remained an important goal in order to understand the relationships between their sources, transport, molecular identities and transformations, and their impacts and fates in the environment. The importance of organic aerosols to climate and biogeochemical cycling has been well documented (Andreae and Crutzen, 1997; Andreae and Gelencsér, 2006; Bond et al., 2013; Booth et al., 2012; Crutzen and Andreae, 1990; Jacobson, 2000; Ramanathan et al., 2001). The specific molecular nature of organic aerosols directly influences the impact they have on the environment. For example, light absorption is caused by electronic transition associated with molecular double bonds, and the number of double bonds and aromatic rings present within the structure has been linked to the ability of that molecule to absorb ultraviolet or visible light (Andreae and Gelencsér, 2006). Given the connections between chemical characteristics and environmental impact, establishing the relationship between aerosol organic matter (OM) source and associated chemical characteristics is important for modeling and predicting the net impact they have on environmental systems. To date, uncertainties in the molecular makeup of organic aerosols limit our ability to make these linkages between aerosol OM source, chemical characteristics, and environmental impact.

Between 10-90\% of total aerosol mass is comprised of OM (Jimenez et al., 2009; Kanakidou et al., 2005; and 
references within), and $10-70 \%$ of that $\mathrm{OM}$ is water-soluble (Decesari et al., 2007; Kleefeld et al., 2002; Sullivan et al., 2004; Zappoli et al., 1999) depending on its physical and chemical composition. A suite of analytical techniques have provided bulk and specific chemical information about carbonaceous species present within fractions of atmospheric OM samples (Hallquist et al., 2009), including ambient aerosols, fog water and rainwater, and laboratorygenerated secondary organic aerosols (SOA). These efforts have shown aerosol OM to be made up of a highly diverse suite of oxygenated compounds that include aliphatic and conjugated functional groups (e.g., Decesari et al., 2007; Jimenez et al., 2009; Mayol-Bracero et al., 2002; Wozniak et al., 2008), which influence the water solubility as well as the light-absorbing capacity of the compounds (Andreae and Gelencsér, 2006; Robertson and O'Reilly, 1987). Recently, ultrahigh-resolution mass spectrometry has shown an extraordinary capacity for characterizing aerosol OM, and is the only current technique able to provide elemental formula information for the thousands of compounds present within individual ambient aerosols (Lin et al., 2012; Mazzoleni et al., 2012; Reemtsma et al., 2006; Schmitt-Kopplin et al., 2010; Wozniak et al., 2008) and laboratory-generated aerosols (Bateman et al., 2010; Heaton et al., 2009; Laskin et al., 2010; Reinhardt et al., 2007) without prior chromatographic separation. In addition to oxygenated compounds, many other functionalized species, including those containing nitrogen and sulfur, have been identified in ambient aerosols, fog water (LeClair et al., 2012; Mazzoleni et al., 2010), and rainwater (Altieri et al., 2012; Altieri et al., 2009; Mitra et al., 2013) from various sources.

Numerous publications characterize some fraction of aerosol OM using various solvent systems, ionization sources, and mass analyzers. To date, much of the work has focused on the water-soluble fraction, leaving little information regarding the water-insoluble fraction that comprises 30-90\% of the OM (Decesari et al., 2007; Kleefeld et al., 2002; Sullivan et al., 2004; Zappoli et al., 1999). Radiocarbon data for organic aerosols collected in rural environments suggest that much of the water-insoluble carbon is fossil-derived and from anthropogenic sources, whereas the water-soluble carbon is contemporary and biogenically derived (Szidat et al., 2004; Wozniak et al., 2012a, b). Limiting molecular analysis to the water-soluble OM (WSOM) means that a quantitatively important component of organic aerosols is missing. Studies have examined the methanolsoluble (Heaton et al., 2009) and acetonitrile-soluble (Bateman et al., 2010; Heaton et al., 2009) fractions of SOAs and other laboratory-generated aerosols. Studies of SOA, which are thought to be highly water-soluble, have shown that the water- and acetonitrile-extracted OM fractions are extremely similar at the molecular level (Bateman et al., 2010; Heaton et al., 2009). However, Bateman et al. (2010) examined a laboratory-generated biomass burning aerosol and determined that the acetonitrile-soluble component of aerosol OM had characteristically lower oxygen-to-carbon $(\mathrm{O} / \mathrm{C})$ ratios than the water-soluble component, suggesting molecular differences between water-soluble and solvent-soluble components of some organic aerosols. These differences imply that the water-insoluble materials in aerosol OM have molecular characteristics distinct from water-soluble OM. However, the differences in water-insoluble and water-soluble aerosol OM have still not been extensively explored.

In the present study we evaluate the specific molecular composition of the water-insoluble fraction of ambient aerosol OM. We employ Fourier transform ion cyclotron resonance mass spectrometry with negative electrospray ionization (ESI-FTICR-MS) for molecular characterization and nuclear magnetic resonance (NMR) spectroscopy for additional structural characterization. We select pyridine and acetonitrile - two solvents that exhibit different polarities than water, have different solvating characteristics, and are compatible with ESI-FTICR-MS and NMR.

Three ambient aerosol particulate samples were collected from a coastal Virginia (USA) site influenced by a mixture of anthropogenic and biogenic aerosol OM sources typical to the east coast of the United States. The suitability of pyridine and acetonitrile as solvents for characterizing aerosol waterinsoluble organic matter (WIOM) by ESI-FTICR-MS was established by comparing the molecular formulas assigned to the pyridine-soluble organic matter (PSOM), acetonitrilesoluble organic matter (ASOM), and WSOM extracts of these ambient aerosol particulate samples.

\section{Methods}

\subsection{Sample collection}

Three ambient aerosol total suspended particulate (TSP) samples were collected during the summer (16-17 August 2011, 24-25 June 2013, and 25-26 June 2013) at the Virginia Institute of Marine Science in Gloucester Point, Virginia $\left(37.2482^{\circ} \mathrm{N}, 76.5005^{\circ} \mathrm{W}\right)$. Air was drawn through a pre-combusted $\left(4 \mathrm{~h}, 475^{\circ} \mathrm{C}\right)$ quartz microfiber filter (Whatman QM/A, $20.3 \times 25.4 \mathrm{~cm}, 419 \mathrm{~cm}^{2}$ exposed area, $0.6 \mu \mathrm{m}$ effective pore size) using a TSP high-volume air sampler (model GS2310, Thermo Andersen, Smyrna, GA) at an average flow rate of $0.81 \mathrm{~m}^{3} \mathrm{~min}^{-1}$. Air particles were collected for $24 \mathrm{~h}$ with total air volumes ranging between 1124 and $1169 \mathrm{~m}^{3}$, and are expected to have contributions from several nearby biogenic and anthropogenic sources (e.g., estuarine waters, natural vegetation, light vehicle traffic, oil refinery, coal-fired power plant), as is typical of the eastern United States. The samples were transferred to a pre-combusted foil pouch immediately after collection and stored at $-8^{\circ} \mathrm{C}$ until analysis. A new and pre-combusted QM/A filter blank was stored under identical conditions to the sample, and was analyzed as a storage filter blank for the 2011 sample. A new and pre-combusted QM/A filter was attached to the air sampler 
immediately prior to the 2013 sampling (24 June 2013) and then stored under identical conditions to the samples, and was analyzed as a field filter blank for the 2013 samples.

\subsection{Aerosol mass and carbon measurements}

The QM/A filters were weighed before and after sampling to determine the total aerosol mass (24.3-29.7 mg TSP) and concentration $\left(20.8-26.2 \mu \mathrm{g} \mathrm{m}^{-3}\right)$. Triplicate aerosol core plug $\left(2.84 \mathrm{~cm}^{2}\right.$ area) samples were acidified to remove inorganic carbon by treating the plugs with $1 \mathrm{M} \mathrm{HCl}$ followed by drying in an oven $\left(4 \mathrm{~h}, 80^{\circ} \mathrm{C}\right)$. Acidified filter plugs were evaluated for total carbon $(\mathrm{C}=$ organic + elemental/black - inorganic carbonates) and nitrogen $(\mathrm{N})$ content using a FlashEA 1112 elemental analyzer (ThermoFinnigan). Quantification was achieved using an aspartic acid standard calibration curve. Acidified blank QM/A filters were evaluated for blank subtraction; however, $\mathrm{C}$ and $\mathrm{N}$ quantities for all of the blank QM/A filter plugs were below the detection levels of the instrument.

\subsection{Solvent extractions}

Replicate solvent extracts of the aerosols and the respective filter blank were obtained by combining three aerosol plugs or blank plugs (three aerosol plugs contain between 0.116 and $0.147 \mathrm{mg} \mathrm{C}$ ) with either $15 \mathrm{~mL}$ of water (Millipore Synergy Ultrapure Water System), $5 \mathrm{~mL}$ of pyridine (Acros, $99+\%$ ), or $5 \mathrm{~mL}$ of acetonitrile (Fisher Optima, 99.9\%) and thoroughly mixed on an orbital shaker table (150 RPM, $4 \mathrm{~h}$, $21{ }^{\circ} \mathrm{C}$ ). Insoluble particles were filtered out using a syringe filter with a pre-combusted glass fiber filter $(0.7 \mu \mathrm{m}$ pore size). The water extracts were then desalted in order to remove salts that can limit the ionization of OM by ESI and concentrated using an established procedure for Agilent PPL solid-phase extraction cartridges (Dittmar et al., 2008). PPL is expected to retain $60-75 \%$ of OM (Dittmar et al., 2008; Stubbins et al., 2012). Low-molecular-weight and exceptionally hydrophilic compounds are expected to be among the losses. Compounds with a low molecular weight $(<200$ Da) are not detected under the FTICR-MS conditions used here, so the negative effects of PPL extraction are expected to be minimal. The desalted sample was eluted in $5 \mathrm{~mL}$ of methanol (WSOM, Acros, 99.9\%). The pyridine filtrate (PSOM) and acetonitrile filtrate (ASOM) did not require further manipulation, and all three extracts were thus prepared so that the final solutions had the same filter-plug-to-solvent volume ratio (three plugs in $5 \mathrm{~mL}$ of solvent). Samples were stored at $-8^{\circ} \mathrm{C}$ until FTICR-MS analysis, typically within $24 \mathrm{~h}$ of preparation.

\subsection{Extraction efficiency determinations}

The filtrates from the water extracts were evaluated for nonpurgeable organic carbon using a Shimadzu TOC-VCPH analyzer to determine water-soluble organic carbon (WSOC) content (Wozniak et al., 2008, 2012a). The WSOC content was then compared with the total aerosol organic carbon content, with the result that $54-60 \%$ of the total aerosol organic carbon was WSOC.

An important aspect of choosing a suitable solvent for WIOM characterization is its extraction efficiency, which could not be accurately determined for acetonitrile and pyridine using standard TOC analysis. Upon evaporation of solvent extracts, these organic solvents adhere to natural organic matter, artificially inflating the carbon content in acetonitrile and pyridine extracts. Therefore, a method was developed based on ${ }^{1} \mathrm{H}$ NMR using glucose $(98 \%$, Acros Organics) as a standard, which is $100 \%$ soluble in pyridine at low concentrations $\left(<1 \mathrm{mg} \mathrm{mL}^{-1}\right)$. Acetonitrile interferes with our ${ }^{1} \mathrm{H}$ NMR quantification strategy due to a strong signal from acetonitrile hydrogen (occurring at $\sim 2 \mathrm{ppm}$ ) that overlaps with the signal from OM (occurring between 0.1 and $4.4 \mathrm{ppm}$ ). This overlapping signal impedes our ability to determine the amount of proton signal derived from the sample and precludes a reliable calculation of extraction efficiency for acetonitrile. A known mass of glucose was dissolved into pyridine- $\mathrm{D}_{5}$ ( $100 \%$ atom $\mathrm{D}$, Acros Organics), providing known carbon and hydrogen concentrations to compare to ${ }^{1} \mathrm{H}$ NMR spectra. Aerosol plugs of known OC masses were each dissolved into pyridine- $\mathrm{D}_{5}$ and water. The WSOM and PSOM samples were then subjected to ${ }^{1} \mathrm{H}$ NMR spectroscopy using a Bruker Daltonics $400 \mathrm{MHz}$ NMR with a $\mathrm{BBI}$ probe. WSOM samples were diluted using $\mathrm{D}_{2} \mathrm{O}(100 \%$ atom D, Acros Organics) at a ratio of $90: 10 \mathrm{WSOM}: \mathrm{D}_{2} \mathrm{O}$. PSOM samples were analyzed in a solvent system of $100 \%$ pyridine- $\mathrm{D}_{5}$. All samples were analyzed for 4000 scans using a standard Bruker water-suppression pulse program, where the $90^{\circ}$ pulse and the transmitter offset were optimized individually for each sample.

The signals obtained from ${ }^{1} \mathrm{H}$ NMR spectra were integrated over the range of 0.1 to $4.4 \mathrm{ppm}$ to get a total signal response, and also integrated over three ranges of chemical shifts to determine contributions from the major proton types (Moretti et al., 2008; Shakya et al., 2012).The major proton types include aliphatic hydrogen ( $\mathrm{H}-\mathrm{C}, 0.6-1.8 \mathrm{ppm}$ for WSOM and 0.7-1.95 ppm for PSOM), unsaturated alkyl or hydrogen to unsaturated carbons $(\mathrm{H}-\mathrm{C}-\mathrm{C}=, 1.8-3.2 \mathrm{ppm}$ for WSOM and 1.95-3.2 ppm for PSOM), and oxygenated aliphatic hydrogen including alcohol, ether, and ester function groups (H-C-O, 3.2-4.4 ppm in WSOM and PSOM). Though aromatic protons $(6.5-8.2 \mathrm{ppm})$ are used in other studies, we omit them from analysis due to the interference of exchanged protons in the pyridine- $\mathrm{D}_{5}$ solvent. The region of 0.1-4.4 ppm is appropriate for this study because it is free of signals from the solvent and contains the majority of signal for these types of samples. The signal response for each proton region was normalized to the total signal response between 0.1 and 4.4 to establish the percent contribution for each proton type. These percentages were used to calculate the average $\mathrm{H} / \mathrm{C}$ ratio for each sample to be used to convert 
hydrogen to carbon content (Table S1 in the Supplement). An $\mathrm{H} / \mathrm{C}$ ratio of 2 is used for the aliphatic hydrogen and unsaturated alkyl hydrogen, and an $\mathrm{H} / \mathrm{C}$ ratio of 1.1 is used for the oxygenated aliphatics (Decesari et al., 2007; Moretti et al., 2008; Shakya et al., 2012).

The signals were used for glucose protons dissolved in pyridine- $\mathrm{D}_{5}$ to establish a glucose response factor (area per mass unit hydrogen). The total area between 0.1 and $4.4 \mathrm{ppm}$ in each sample was converted into a mass of dissolved hydrogen using the glucose response factor. The dissolved hydrogen mass was converted to dissolved carbon mass using the calculated average $\mathrm{H} / \mathrm{C}$ ratio (1.94-1.98). Comparison of the calculated dissolved carbon amount to the starting mass of carbon gives a relative percentage of extractable organic matter. Details on these values are provided in Table S2 in the Supplement.

\subsection{ESI-FTICR-MS}

Immediately prior to analysis, the WSOM replicates (in methanol) and filter blank extract were diluted by 2 using LC/MS-grade water with a small amount $(<0.1 \%$ total volume) of ammonium hydroxide to enhance ionization efficiency. The PSOM, ASOM, and respective filter blank extracts were diluted by 2 using methanol with a small amount ( $<0.1 \%$ total volume) of ammonium hydroxide. Prior to sample analysis, the instrument was externally calibrated using a polyethylene glycol standard. Each of the samples was introduced to an Apollo II electrospray ionization source (negative ion mode) at a flow rate of $120 \mathrm{~nL} \mathrm{~min}^{-1}$ on a Bruker Daltonics 12 Tesla Apex Qe FTICR-MS housed at the College of Sciences Major Instrumentation Cluster at Old Dominion University. Spray voltages were optimized for each sample. Ions were accumulated in the hexapole for 0.5$2.0 \mathrm{~s}$ before transfer into the ICR cell, where exactly 300 transients were co-added. Experimental duplicates were evaluated for each aerosol sample and solvent mixture to ensure good experimental and instrumental reproducibility.

\subsection{Data processing}

Each spectrum was calibrated internally using naturally occurring molecules (fatty acids, dicarboxylic acids, and other homologous series with only carbon, hydrogen, and oxygen in the molecular formula) within the sample (Sleighter et al., 2008). Salt peaks (mass defect $0.4-0.98$ for $m / z<400$, and mass defect $0.6-0.97$ for $m / z>400$ ), blank peaks (those present in the respective QM/A filter blank), and ${ }^{13} \mathrm{C}$ isotopologue peaks were removed from each mass list prior to formula assignments. Additionally, each set of duplicates was evaluated for common $m / z$, where only common $m / z$ were used for molecular formula assignments. Each set of duplicates was threshold-corrected for peaks that were below the $S / N 3$ threshold but above $S / N 2.5$ (for example, if a peak was present at $S / N 3.1$ in one sample, and $S / N 2.9$ in the second sample, then it was considered common; Sleighter et al., 2012). This corrects for minor differences in peak magnitude that may cause a peak to go undetected when it is present at a magnitude slightly below the method detection limit. Each set of duplicates had more than $67 \%$ of the peaks (300$600 \mathrm{~m} / \mathrm{z}$ ) in common, indicating good instrumental and experimental reproducibility (Sleighter et al., 2012).

Molecular formulas were assigned to $m / z$ common to duplicates using an in-house MatLab (The MathWorks Inc., Natick, MA) code according to the criteria ${ }^{12} \mathrm{C}_{5-50},{ }^{1} \mathrm{H}_{5-100}$, ${ }^{14} \mathrm{~N}_{0-5},{ }^{16} \mathrm{O}_{1-30},{ }^{32} \mathrm{~S}_{0-2}$, and ${ }^{31} \mathrm{P}_{0-2}$, where the subscripts indicate the range of atoms allowed in a formula. The assigned formulas were screened to eliminate any chemically unreasonable formulas for naturally occurring organic compounds. The criteria for formula assignments are consistent with published procedures (Stubbins et al., 2010; Wozniak et al., 2008). Most (79-96\%) of the common peaks between 200 and $800 \mathrm{~m} / z$ could be assigned a formula. A large majority (>90\%) of the formulas are within $0.5 \mathrm{ppm}$ agreement of the measured $\mathrm{m} / \mathrm{z}$, and all formulas are within $1 \mathrm{ppm}$ error.

\section{Results and discussion}

\subsection{NMR spectroscopy}

One of the initial concerns for this comparison was to determine whether the organic solvents chosen were as effective as water for removing OM from aerosol particulates. We resorted to ${ }^{1} \mathrm{H}$ NMR spectroscopy to evaluate the relative proportion of OM extracted by water and pyridine. Pyridine has been demonstrated to extract significant quantities of macromolecular OM from natural samples that have distinctly low water solubility (e.g., coals, soils, kerogen, etc.; McKee and Hatcher, 2010; Salmon et al., 2011; Wu et al., 2003). Extracts of pyridine lend themselves well to recovery estimates using ${ }^{1} \mathrm{H}$ NMR. By integrating the peaks in the main resonance absorption region of the spectrum of aerosol PSOM, between 0.1 and $4.4 \mathrm{ppm}$, we determined the area response from the sample and used the glucose response factor (area per mass unit of hydrogen) to determine the amount of carbon present in the PSOM. The starting mass of carbon for each aerosol is known, and the percentage of extractable carbon, and therefore extractable OM, could be determined. We determined that $31-59 \%$ of the aerosol OM is soluble in pyridine, which is comparable to what is found for WSOM (54-60\%). We recognize that assumptions were made in order to determine these values, and that OM solubility in pyridine will vary with sample type; however, we are confident in these values due to the matched signal response in both PSOM and WSOM samples.

Acetonitrile has been used in the characterization of laboratory-generated aerosol OM in previous studies (Bateman et al., 2008, 2010; Heaton et al., 2009; Laskin et al., 2010; Reinhardt et al., 2007) and is examined by FTICR-MS 
a) WSOM

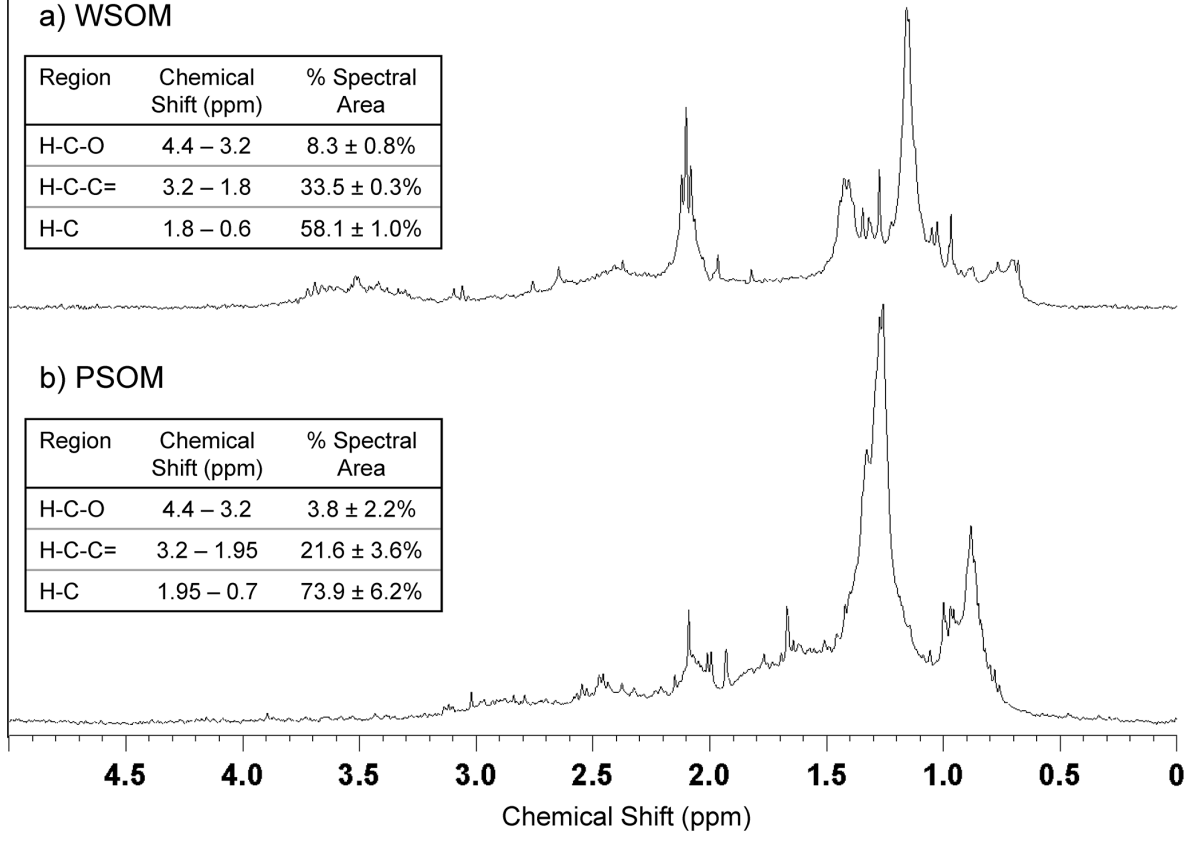

Figure 1. Expanded ${ }^{1} \mathrm{H}$ NMR spectra between 0 and 5 ppm for (a) WSOM and (b) PSOM for the aerosol particulate sample collected 25-26 June 2013. The table insets give the chemical shifts and average relative intensities (normalized to total intensity between 0 and $4.4 \mathrm{ppm}$ ) and standard deviations for the three aerosol samples in the major proton regions, including aliphatic $(\mathrm{H}-\mathrm{C})$, unsaturated $(\mathrm{H}-\mathrm{C}-\mathrm{C}=)$, and oxygenated aliphatics (H-C-O).

in this study for this reason. We did not evaluate the acetonitrile extraction efficiency by NMR because this solvent displays its main signal in the 0.1 to $4.4 \mathrm{ppm}$ region and a comparison like the one made with pyridine was not feasible. However, we can speculate that the efficiency is comparable to that of water and pyridine, considering its relative polarity as a solvent.

While the primary motivation for obtaining ${ }^{1} \mathrm{H}$ NMR spectra was to evaluate extraction efficiencies, the information contained therein is valuable for bulk characterization. A more detailed structure characterization is beyond the scope of this manuscript but will be the subject of future work. Figure 1 shows the ${ }^{1} \mathrm{H}$ NMR spectra for the WSOM and PSOM fractions for one of the aerosol samples (collected 2526 June 2013), and the table inset gives the chemical shifts and average relative intensities (for all three aerosol samples) and standard deviations. Both spectra are dominated by aliphatic signals if one does not consider the strong resonances in the aromatic region of the PSOM spectrum assigned to pyridine protons. The peak positions are different for PSOM, giving the impression that functionalized structures in WSOM are different from those of PSOM. For example, the methylenic peak $\left(\mathrm{CH}_{2}\right)$ in WSOM spectrum falls between 1.1 and $1.2 \mathrm{ppm}$, and is between 1.2 and 1.5 in the PSOM spectrum. However, it is likely that we are observing peak shifts due to solvent interactions (Sanders and Hunter, 1993), and some of the peaks in the PSOM spectrum are shifted downfield with respect to the WSOM spectrum. The majority of the signal is due to aliphatic hydrogen in both spectra. However, this group is proportionally of greater intensity (73.9\% of spectral intensity) in the PSOM spectrum relative to all other resonances. Methyl protons $\left(\mathrm{CH}_{3}\right.$ at $0.7-$ $0.8 \mathrm{ppm}$ for WSOM and $0.8-0.9 \mathrm{ppm}$ for PSOM) are nearly in the same relative proportions to methylenic $\left(\mathrm{CH}_{2}\right.$ at $1.1-$ $1.2 \mathrm{ppm}$ for WSOM and 1.2-1.5 ppm for PSOM) protons in both extracts $\left(\mathrm{a} \mathrm{CH}_{2} / \mathrm{CH}_{3}\right.$ ratio of 4 for both WSOM and PSOM). This suggests aliphatic structures of similar chain lengths.

Additional differences between the WSOM and PSOM spectra are found in the regions downfield of $1.7 \mathrm{ppm}$, regions typically associated with protons near electronwithdrawing functional groups (e.g., hydroxyl, carboxyl, carbonyl, and amino groups). The WSOM extract shows higher relative peak areas in this region, which is evidence for a greater relative abundance of these types of resonances. Protons found in this region make up $41.8 \%$ of the spectral area for WSOM and $25.4 \%$ of the spectral area for PSOM. The peaks between 2.0 and $2.8 \mathrm{ppm}$ in both spectra are characteristic of hydrogen attached to a carbon alpha to an unsaturated carbon ( $\mathrm{H}-\mathrm{C}-\mathrm{C}=$ ), which represent alkenes and carbonyl groups. The relative abundance is higher in the WSOM than PSOM (33.5 and $21.6 \%$, respectively). This higher abundance suggests that WSOM is more selective for unsaturated compounds, which absorb light (Andreae and 


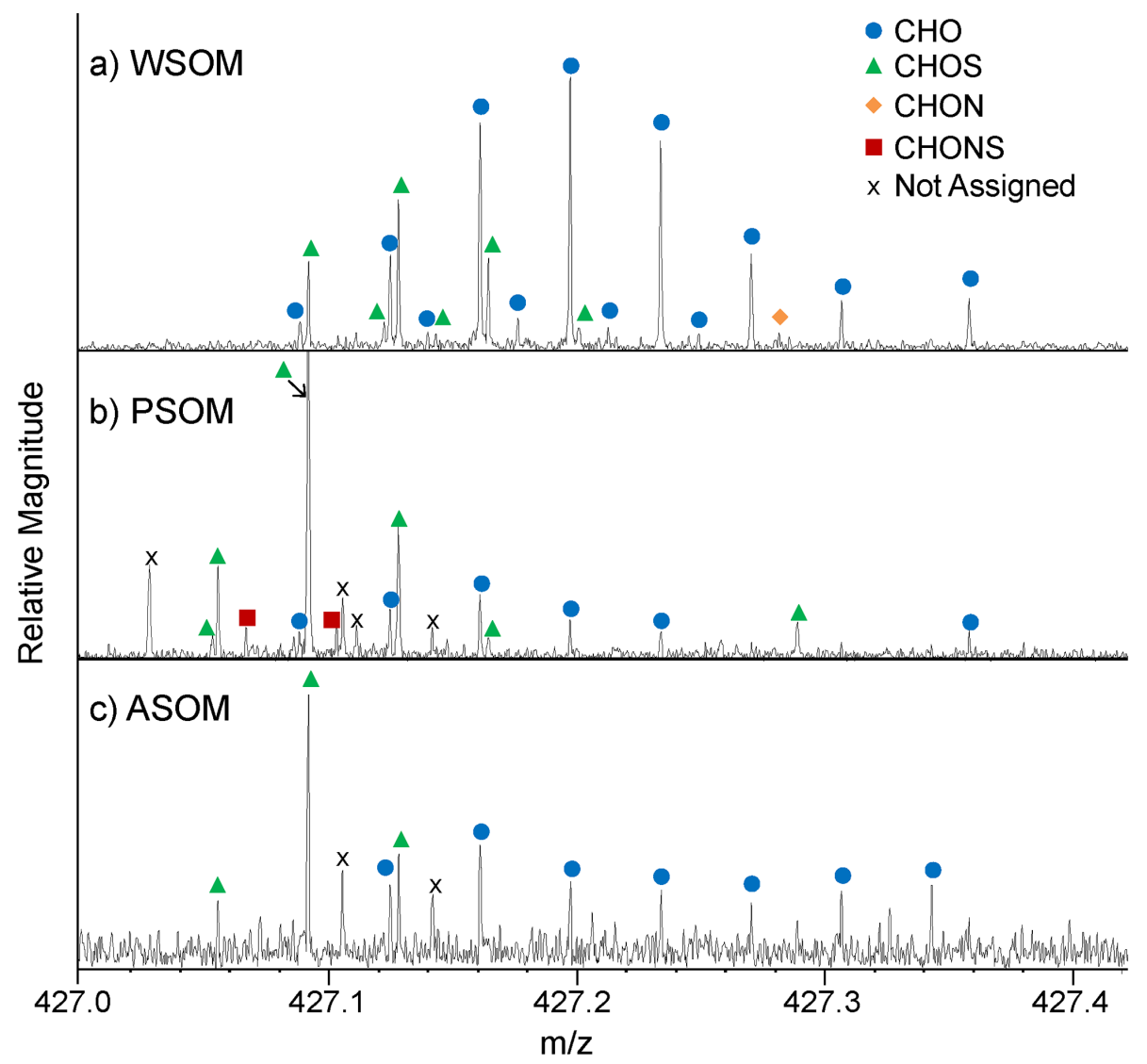

Figure 2. FTICR mass spectra expanded for $m / z$ at a nominal mass of 427 for (a) WSOM, (b) PSOM and (c) ASOM. Peaks with $S / N \geq 3$ have a colored shape above the peak to indicate the elemental makeup of the assigned molecular formula. Blue circles represent $\mathrm{CHO}$ formulas, green triangles represent $\mathrm{CHOS}$ formulas, orange diamonds represent $\mathrm{CHON}$ formulas, red squares represent $\mathrm{CHONS}$ formulas, and a black " $\mathrm{x}$ " denotes $\mathrm{m} / \mathrm{z}$, that did not have a formula assigned under the chosen criteria.

Gelencsér, 2006), and WSOM may contribute more light absorption on a per carbon basis than PSOM. The broad peak between 3.2 and $4.0 \mathrm{ppm}$ in the WSOM spectrum is attributed to hydrogen attached to carbon adjacent to oxygen, or nitrogen could represent polyols, carbohydrate-like materials, or peptide-like materials. Their relative abundance in the PSOM spectrum is less than in the WSOM spectrum (3.8 vs. $8.3 \%$ spectral intensity), demonstrating that the two solvents extract chemically distinct portions of aerosol OM. The NMR spectral information thus shows a greater preponderance of signals from protons near functionalized structures and unsaturated carbons in the WSOM and a higher relative signal for aliphatic protons in the PSOM.

\subsection{Mass spectra and molecular formula characteristics}

The ESI-FTICR mass spectra for ambient aerosol WSOM are comparable to previously published FTICR-MS spectra of aerosol WSOM extracts (Lin et al., 2012; Mazzoleni et al., 2012; Schmitt-Kopplin et al., 2010; Wozniak et al., 2008), averaging thousands of peaks across a broad range of 200 $800 \mathrm{~m} / z$; the PSOM and ASOM also contained thousands of peaks across the same mass range. A representative full spectrum for each solvent can be found in the Supplement (Fig. S1 in the Supplement). There are clear spectral differences between the WSOM and the solvent extracts (i.e., PSOM and ASOM), including differences in the presence of some peaks, as well as the relative magnitudes of common peaks (Fig. 2).

Figure 2 shows a WSOM, PSOM, and ASOM spectra for one of the aerosol samples (collected 16-17 August 2011) expanded at a single nominal mass $(m / z=427)$. This distribution of peak intensities is representative of odd nominal masses across the spectral range. Each of the peaks with $S / N$ of at least 3 is labeled with colored shapes to denote the elemental makeup of the assigned molecular formula. There are a few peaks that were not assigned a molecular formula because no chemically reasonable formula was possible using the given criteria, suggesting these molecular formulas contain elements other than $\mathrm{C}, \mathrm{H}, \mathrm{N}, \mathrm{O}, \mathrm{S}$, and/or P. A Kendrick mass defect plot for formulas differing by a $\mathrm{CH}_{2}$ group (Fig. S2 in the Supplement; Kendrick, 1963) shows that the formulas identified in Fig. 2 are involved in 
Kendrick mass defect series that span nearly the entire mass range $(200-800 \mathrm{~m} / \mathrm{z})$. One of the striking differences is the presence of more peaks at the low mass defect region (below $427.1 \mathrm{~m} / \mathrm{z}$ ) in the PSOM (Fig. 2b). PSOM has the most peaks in this low mass defect region (masses having a decimal less than 0.1) throughout the entire spectrum when compared to WSOM and ASOM (Fig. S3 in the Supplement). Peaks with low mass defect are either deficient in hydrogen or rich in oxygen, which suggests that PSOM contains either more unsaturated formulas or more highly oxygenated species than does the WSOM. Those specific peaks at $427.05294 \mathrm{~m} / \mathrm{z}$ and $427.05518 \mathrm{~m} / \mathrm{z}$ represent CHOS compounds with high $\mathrm{O} / \mathrm{C}$ ratios (>0.4) and moderate $\mathrm{H} / \mathrm{C}$ ratios (1.0-1.5), indicating that the selectivity is likely due to the compounds being more highly oxygenated rather than hydrogen-deficient. In addition to peak presence and absence, there is a difference in the peak intensity distributions between the three solvents. The most intense peak in the WSOM (Fig. 2a) is in the center of all peaks for that nominal mass at $427.19723 \mathrm{~m} / \mathrm{z}$, and has been assigned as a formula containing only $\mathrm{CHO}$ $\left(\mathrm{C}_{21} \mathrm{H}_{32} \mathrm{O}_{9}\right)$. This peak is present in both ASOM and PSOM, but the relative intensity is considerably lower. The most intense peak $(427.09168 \mathrm{~m} / \mathrm{z})$ in the ASOM and PSOM is a CHOS formula $\left(\mathrm{C}_{15} \mathrm{H}_{24} \mathrm{O}_{12} \mathrm{~S}\right)$ located at a lower mass defect than the most intense peak in the WSOM spectrum. This peak is also present in WSOM, but at a much lower relative intensity. These differences in relative magnitude of peaks and the presence or absence of some peaks reflect the differences in the ability of these three solvents to extract and detect certain compounds. Recently, the relative magnitude of peaks for compounds detected using ESI-FTICR-MS have been shown to be quantitatively significant and reproducible in a consistent solvent system (Kamga et al., 2014), and have also been used to highlight the differences in sample composition in ESI-FTICR-MS studies of aerosol OM (e.g., Mazzoleni et al., 2012). However, differences in solvent composition have not been evaluated to determine how the solvent affects ESI efficiency, so the remainder of the discussion of the data focuses on differences in presence and absence of peaks in water, pyridine, and acetonitrile extracts to provide a qualitative view of WIOM components detected by ESIFTICR-MS.

The majority of the detected peaks in each extract were assigned molecular formulas within $0.5 \mathrm{ppm}$ error. All of the assigned formulas present in any of the three aerosol samples were combined for each of the three solvents to generate master lists containing every molecular formula assigned to each WSOM, PSOM, and ASOM. Additionally, the master lists for the three solvents were combined to evaluate the molecular properties of the aerosol sample as a whole. The master lists for each solvent were compared for distinct molecular characteristics. The molecular characteristics for each solvent are arranged by their elemental makeup (e.g., number and percentage of $\mathrm{CHO}$ formulas) and numerical averages for $\mathrm{O} / \mathrm{C}, \mathrm{H} / \mathrm{C}$, and a modified aromaticity index
( $\mathrm{AI}_{\text {mod }}$, Eq. (1) shown in Table 1). For simplicity and due to low number frequency, all formulas containing phosphorus (CHOP, CHONP, and CHOSP) have been grouped together and reported as $\mathrm{CHOP}(\mathrm{N}, \mathrm{S})$. $\mathrm{AI}_{\text {mod }}$ is a metric established by Koch and Dittmar (2006) that estimates the degree of aromaticity of an organic compound using only its molecular formula. $\mathrm{AI}_{\mathrm{mod}}$ is calculated as follows:

$\mathrm{AI}_{\text {mod }}=\frac{1+\mathrm{C}-0.5 \mathrm{O}-\mathrm{S}-0.5 \mathrm{H}}{\mathrm{C}-0.5 \mathrm{O}-\mathrm{S}-\mathrm{N}-\mathrm{P}}$

for any molecular formula comprised of $\mathrm{C}, \mathrm{H}, \mathrm{N}, \mathrm{O}, \mathrm{S}$, and $\mathrm{P}$. $\mathrm{AI}_{\text {mod }}$ is similar to other aromaticity metrics, such as carbonnormalized double-bond equivalent (Hockaday et al., 2006), and it includes heteroatoms as points of unsaturation and conservatively assumes that half of all O's participate in a double bond, such as that of a carbonyl group. A low $\mathrm{AI}_{\text {mod }}$ indicates a low degree of aromaticity, where a value of zero is an aliphatic compound, a value between 0 and 0.5 is representative of olefinic compounds (containing at least one double bond) and includes alicyclic molecules. A high $\mathrm{AI}_{\text {mod }}$ indicates a higher degree of aromaticity where a compound having a value above 0.5 is aromatic, and a value of 0.67 or higher indicates condensed aromatic compounds (fused aromatic rings; Koch and Dittmar, 2006). Aromatic and condensed aromatic compounds play an important role in the light-absorbing ability of organic aerosols (Andreae and Gelencsér, 2006).

Before analyzing the molecular properties of the individual solvents, every molecular formula (5106 formulas total) assigned to any of the three solvents was combined to evaluate the aerosol samples as a whole. The Venn diagram shown in Fig. 3a shows the percentage of the total formulas unique to each of the solvents, as well as the ones found in one or more of the solvents. Of all the formulas, WSOM analyzes the largest fraction $(3396,67 \%)$. There are 3152 formulas (62\%) identified in ASOM, and 2397 formulas (47\%) found in PSOM. There are many formulas common between WSOM and the organic solvent extracts, where 1077 formulas $(21 \%)$ are found in all three solvents, $1367(27 \%)$ are common with PSOM, and $2072(41 \%)$ are common with ASOM. There are 1710 formulas (33\%) found in the PSOM and/or ASOM spectra that are not present in WSOM spectra (Fig. 3a). The formulas present in ASOM and/or PSOM, but not in WSOM, are representative of compounds that are either (1) not water-soluble or (2) outside the analytical window of WSOM using ESI-FTICR-MS. Because of this, we refer to these compounds as "water-insoluble" organic matter (WIOM). It is important to emphasize that the ability of a compound to be detected by ESI-FTICR-MS is highly dependent on its ability to be ionized by negative electrospray ionization; thus any compound that does not contain a polar ionizable functional group (e.g., hydrocarbons) will not be analyzed in any of the solvents and some unknown portion of WIOM will go undetected. One thing to note is that $67 \%$ of the formulas are found in WSOM, suggesting that 
a)

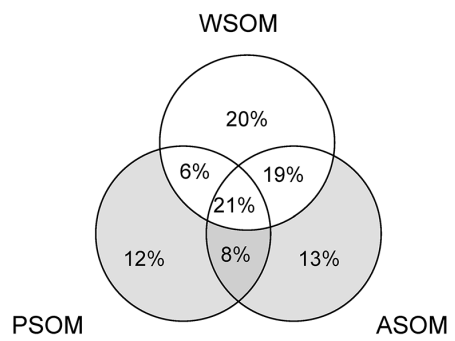

b)

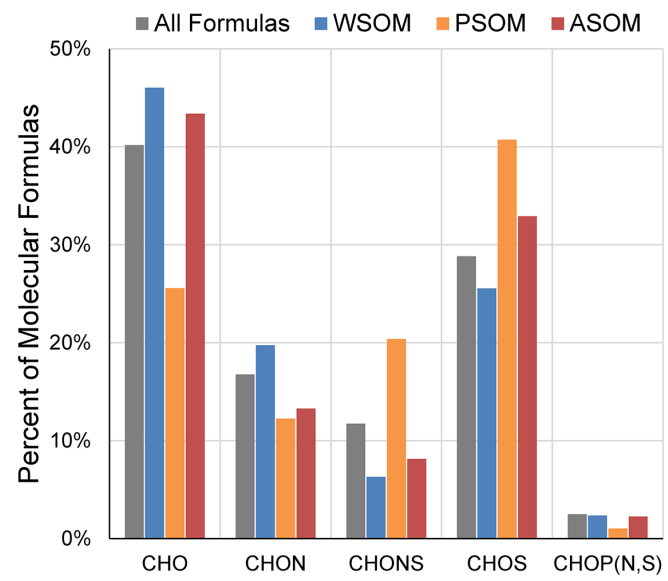

c)

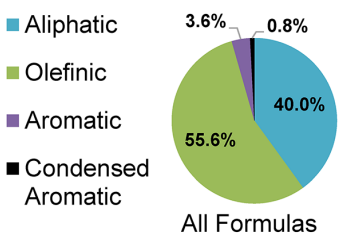

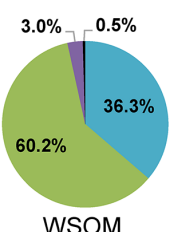
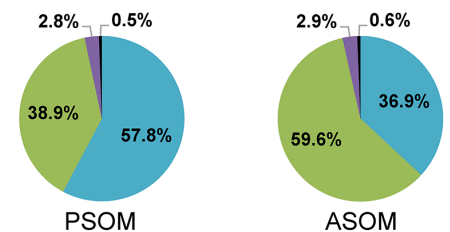

Figure 3. (a) Venn diagram showing the relative distributions of all molecular formulas (5106 total) present in any of the three solvents; grey areas represent WIOM. Percentages in areas of overlap are percentages of molecular formulas that appear in both (or all three) of those samples. Percentages in areas of no overlap are molecular formulas that are unique to that individual sample. (b) Histogram of the fractional contributions (\%) of molecular formulas from various elemental combinations to the total for all formulas (5106 total), WSOM formulas (3396 total), PSOM formulas (2397 total), or ASOM formulas (3152 total). (c) Pie charts showing the fractional contributions (\%) of molecular structure classes as determined by $\mathrm{AI}_{\mathrm{mod}}$ calculations.

WSOM is more complex molecularly than WIOM despite extracting similar amounts of material. This is likely due, in part, to the poor ionization efficiency of aliphatic material and compounds low in oxygen. The ${ }^{1} \mathrm{H}$ NMR of the PSOM shows us that pyridine is selective for more aliphatic compounds and compounds that are not extensively substituted with polar functional groups.

The 5106 individual formulas assigned to the three solvents are made up of $2051 \mathrm{CHO}(40 \%), 1472$ CHOS (29\%), 857 CHON (17\%), 599 CHONS (12\%), and 127 $\mathrm{CHOP}(\mathrm{N}, \mathrm{S})(2.5 \%$, Fig. 3b). Most (>95\%) of the detected compounds are classified as either aliphatic $(40 \%, 2043$ formulas) or olefinic $(56 \%, 2837$ formulas) based on their low $\mathrm{AI}_{\text {mod }}$ values (Fig. 3c). Both anthropogenic and biogenic emission sources release OM that falls under the classification of aliphatic and olefinic, such as alkanes, alkenes, alkanoic acids, alkenoic acids, alkanals, alkenals, and terpenes (Rogge et al., 1993a, b, c), which can act as precursors to SOA. The polar compounds are formed through atmospheric processing reactions (i.e., photooxidation or reaction with $\mathrm{NO}_{\mathrm{x}}$ and $\mathrm{SO}_{\mathrm{x}}$ ) with these biogenically and anthropogenically released precursor molecules (Alfarra et al., 2006; Andreae and Gelencsér, 2006; Jacobson, 2000). Less than $5 \%$ of all formulas are classified as aromatic $(3.6 \%, 183$ formulas) or condensed aromatic ( $0.8 \%, 43$ formulas) based on their high $\mathrm{AI}_{\text {mod }}$. The low abundance of these aromatic species identified in these samples suggests only small contributions from combustion sources, which are known sources of carbonaceous aromatic compounds such as black carbon, oxygenated aromatic compounds, and polycyclic aromatic hydrocarbons. The sampling site from which these aerosols were collected is influenced by local combustion sources (i.e., coal-fired power plant and light vehicular traffic), but not to a large extent. This observation is supported by a previous study of aerosol OM from a similar rural site located $36 \mathrm{~km}$ north of our sampling site. Wozniak et al. (2012b) show that aromatic compounds made up a quantitatively small (less than $1 \%$ on average) component of the total organic carbon and that only half of that aromatic OM was derived from fossil sources (Wozniak et al., 2012b). The small amount of aromatic material in the WSOM sample detected by FTICR-MS is supported by the lack of intensity $(<3 \%$ of total spectral intensity) of peaks that represent aromatic protons (chemical shift 6.5-8.2 ppm) in the ${ }^{1}$ H NMR spectra (Fig. S4a in the Supplement). Unfortunately, aromatic protons from the aerosol OM are not distinguishable from the exchanged protons in the pyridine- $\mathrm{D}_{5}{ }^{1} \mathrm{H}$ NMR spectra (Fig. S4b in the Supplement); 
Table 1. Molecular formula distributions for each solvent extract based on elemental composition with number average characteristics. The values for PSOM and ASOM do not include formulas common with WSOM and thus represent characteristics for WIOM.

\begin{tabular}{|c|c|c|c|c|c|c|}
\hline \multirow[b]{2}{*}{$\begin{array}{l}\text { Solvent } \\
\text { extract }\end{array}$} & \multirow[b]{2}{*}{$\begin{array}{l}\text { Elemental } \\
\text { composition }\end{array}$} & \multirow[b]{2}{*}{$\begin{array}{r}\text { \# of } \\
\text { Formulas }\end{array}$} & \multirow[b]{2}{*}{$\begin{array}{r}\% \text { of } \\
\text { Formulas }\end{array}$} & \multicolumn{3}{|c|}{ Number averages } \\
\hline & & & & $\mathrm{O} / \mathrm{C}$ & $\mathrm{H} / \mathrm{C}$ & $\mathrm{AI}_{\text {mod }}$ \\
\hline \multirow[t]{6}{*}{ WSOM } & $\mathrm{CHO}$ & 1563 & $46 \%$ & $0.43 \pm 0.15$ & $1.43 \pm 0.24$ & $0.17 \pm 0.14$ \\
\hline & $\mathrm{CHON}$ & 671 & $20 \%$ & $0.47 \pm 0.23$ & $1.41 \pm 0.20$ & $0.16 \pm 0.16$ \\
\hline & CHONS & 214 & $6.3 \%$ & $0.71 \pm 0.21$ & $1.65 \pm 0.20$ & $0.02 \pm 0.10$ \\
\hline & CHOS & 868 & $26 \%$ & $0.47 \pm 0.23$ & $1.46 \pm 0.35$ & $0.15 \pm 0.21$ \\
\hline & $\mathrm{CHOP}(\mathrm{N}, \mathrm{S})$ & 80 & $2.4 \%$ & $0.39 \pm 0.09$ & $1.54 \pm 0.14$ & $0.09 \pm 0.10$ \\
\hline & Total & 3396 & $100 \%$ & $0.46 \pm 0.19$ & $1.45 \pm 0.27$ & $0.15 \pm 0.17$ \\
\hline \multirow[t]{6}{*}{$\mathrm{WIOM}_{\mathrm{pyr}}$} & $\mathrm{CHO}$ & 155 & $15 \%$ & $0.29 \pm 0.20$ & $1.59 \pm 0.36$ & $0.13 \pm 0.17$ \\
\hline & $\mathrm{CHON}$ & 101 & $9.8 \%$ & $0.54 \pm 0.32$ & $1.53 \pm 0.42$ & $0.19 \pm 0.21$ \\
\hline & CHONS & 311 & $30 \%$ & $0.64 \pm 0.23$ & $1.52 \pm 0.28$ & $0.07 \pm 0.18$ \\
\hline & CHOS & 442 & $43 \%$ & $0.49 \pm 0.31$ & $1.54 \pm 0.38$ & $0.10 \pm 0.17$ \\
\hline & $\mathrm{CHOP}(\mathrm{N}, \mathrm{S})$ & 21 & $2.0 \%$ & $0.49 \pm 0.18$ & $1.43 \pm 0.50$ & $0.23 \pm 0.29$ \\
\hline & Total & 1030 & $100 \%$ & $0.51 \pm 0.29$ & $1.54 \pm 0.35$ & $0.11 \pm 0.18$ \\
\hline \multirow[t]{6}{*}{$\mathrm{WIOM}_{\mathrm{acn}}$} & $\mathrm{CHO}$ & 428 & $40 \%$ & $0.25 \pm 0.16$ & $1.67 \pm 0.24$ & $0.10 \pm 0.12$ \\
\hline & $\mathrm{CHON}$ & 101 & $9.4 \%$ & $0.48 \pm 0.35$ & $1.66 \pm 0.42$ & $0.12 \pm 0.22$ \\
\hline & CHONS & 136 & $13 \%$ & $0.45 \pm 0.25$ & $1.27 \pm 0.29$ & $0.25 \pm 0.25$ \\
\hline & CHOS & 387 & $36 \%$ & $0.49 \pm 0.32$ & $1.42 \pm 0.36$ & $0.16 \pm 0.20$ \\
\hline & $\mathrm{CHOP}(\mathrm{N}, \mathrm{S})$ & 28 & $2.6 \%$ & $0.42 \pm 0.20$ & $1.49 \pm 0.25$ & $0.14 \pm 0.19$ \\
\hline & Total & 1080 & $100 \%$ & $0.39 \pm 0.28$ & $1.53 \pm 0.35$ & $0.15 \pm 0.19$ \\
\hline
\end{tabular}

therefore, no conclusion can be made about the amount of aromatic compounds in the PSOM based on ${ }^{1} \mathrm{H}$ NMR.

The WSOM mass spectra contain the greatest number of molecular formulas (3396), which are dominated by $\mathrm{CHO}$ $(1563,46 \%)$ and CHOS $(868,26 \%)$ formulas, followed by CHON (671 formulas, $20 \%$ ), CHONS (214 formulas, $6.3 \%$ ), and $\mathrm{CHOP}(\mathrm{N}, \mathrm{S})(80$ formulas, $2.4 \%)$, as displayed in Fig. 3b. This distribution of molecular formulas, specifically the dominance by $\mathrm{CHO}$ formulas, is consistent with other ambient aerosol samples collected in the eastern United States (Wozniak et al., 2008). There are more CHOS than $\mathrm{CHON}$ formulas, suggesting that sulfur species (e.g., $\mathrm{SO}_{4}^{2-}$ ) were important to the atmospheric processes in this region at the time of sampling.

The PSOM contains the fewest number of total formulas (2397); however, the molecular characteristics of PSOM are distinct from that of WSOM or ASOM. PSOM contains mostly CHOS (976 formulas, $41 \%$ ) and $\mathrm{CHO}$ (613 formulas, $26 \%$ ) formulas, followed by CHONS (489 formulas, $20 \%$ ), CHON (294 formulas, $12 \%$ ), and CHOP(N,S) (25 formulas, $1.0 \%$ ) formulas (Fig. 3b). Nearly half of the PSOM formulas (1030 formulas, $43 \%)$ are not found in WSOM $\left(\mathrm{WIOM}_{\mathrm{pyr}}\right)$, indicating that they are either truly water-insoluble compounds or do not ionize well in water due to being suppressed by other WSOM components with higher ionization efficiencies. The $\mathrm{WIOM}_{\mathrm{pyr}}$ is dominated by sulfur-containing species, 442 CHOS (43\%) and 311 CHONS (30\%) for- mulas, with smaller contributions from $\mathrm{CHO}$ (155 formulas, $15 \%$ ), CHON (101 formulas, $9.8 \%$ ), and $\mathrm{CHOP}(\mathrm{N}, \mathrm{S})$ (21 formulas, $2.0 \%$ ) compounds (Table 1). A large majority $(88 \%)$ of the sulfur formulas in the $\mathrm{WIOM}_{\text {pyr }}$ have an $\mathrm{O} / \mathrm{S}$ ratio of at least 4 , suggesting that many of these formulas represent organosulfates and nitrooxyorganosulfates. Additionally, many of the sulfur compounds are aliphatic $(65 \%)$ according to their $\mathrm{AI}_{\text {mod }}$ values. This sulfur predominance suggests that pyridine could be (1) selective towards organic compounds with sulfur as part of its molecular structure and/or (2) selective for aliphatic compounds, which could be more susceptible than unsaturated compounds to reactions with sulfur species that are co-emitted with the carbonaceous aerosols in the atmosphere. A study by SchmittKopplin et al. (2010) showed that compounds with higher $\mathrm{H} / \mathrm{C}$ ratios can react more efficiently with sulfate aerosols to form organosulfates, providing support for the latter of the two possibilities.

The ASOM fraction contains 3152 formulas, and 1080 of those formulas were not assigned to peaks in the WSOM spectra. Like WSOM, the whole ASOM sample is dominated by CHO (1367 formulas, $43 \%$ ) and CHOS (1038 formulas, $33 \%$ ) compounds, followed by CHON (419 formulas, $13 \%$ ), CHONS (257 formulas, $8.2 \%$ ), and CHOP(N,S) (71 formulas, $2.3 \%$, Fig. 3b). The formulas present in ASOM, but not in WSOM (i.e., $\mathrm{WIOM}_{\mathrm{acn}}$ ), show a similar atomic distribution to the WSOM formulas (Table 1), with CHO (428 
formulas, $40 \%$ ) and CHOS (387 formulas, $36 \%$ ) formulas being most abundant, but there are more CHONS (136 formulas, $13 \%$ ) than CHON (101 formulas, $9.4 \%$ ) formulas.

There are 1710 WIOM formulas found in either pyridine or acetonitrile (and not water), and 400 of those formulas are common between the two organic solvents. The formulas common between $\mathrm{WIOM}_{\mathrm{pyr}}$ and $\mathrm{WIOM}_{\mathrm{acn}}$ consist mostly of CHOS (225 formulas, $56 \%$ ) and $\mathrm{CHO}$ (95 formulas, $24 \%$ ) compounds, followed by CHONS (62 formulas, $16 \%$ ) and a few CHON (16 formulas, $4.0 \%)$ and $\mathrm{CHOP}(\mathrm{N}, \mathrm{S})(2$ formulas, $0.5 \%$ ) compounds. The 630 formulas unique to pyridine (i.e., not found in acetonitrile or water) are dominated by sulfur-containing formulas with CHONS (249 formulas, $40 \%$ ) and CHOS (217 formulas, $34 \%$ ), and also contains formulas with CHON (85 formulas, $14 \%$ ), CHO (60 formulas, $10 \%)$, and $\mathrm{CHOP}(\mathrm{N}, \mathrm{S})(19,3.0 \%)$. The 680 formulas unique to acetonitrile are dominated by formulas with only CHO (333 formulas, $49 \%$ ) followed by CHOS (162 formulas, $24 \%$ ), CHON ( 85 formulas, $13 \%$ ), CHONS (74 formulas, $11 \%$ ), and $\mathrm{CHOP}(\mathrm{N}, \mathrm{S})$ (26 formulas, $3.8 \%$ ).

The relative distributions of formulas for each compound class based on molecular structure (as determined by $\mathrm{AI}_{\text {mod }}$ values as described above) is shown in Fig. 3c. WSOM and ASOM contain mostly olefinic compounds $(60 \%$ in each case), and have significant contributions from aliphatic compounds (36 and $37 \%$, respectively). Contrarily, PSOM is dominated by aliphatic formulas $(58 \%)$, with a smaller amount of olefinic compounds (39\%), and this predominance is consistent with the ${ }^{1} \mathrm{H}$ NMR results. In all three extracts, the contributions from aromatic and condensed aromatic compounds are small $(\leq 3.0$ and $\leq 0.6 \%$, respectively). The relative amount of each molecular structure type based on aromaticity index for the $\mathrm{WIOM}_{\mathrm{pyr}}$ and $\mathrm{WIOM}_{\mathrm{acn}}$ are not significantly different than whole PSOM and ASOM, respectively. Unless the WIOM contains a significant portion of non-ionizable (by ESI) aromatic compounds, the WIOM analyzed in this study may not absorb light as efficiently as the WSOM. This is surprising because we expect the insoluble OM (presumably fossil-derived; Wozniak et al., 2012b) to be aromatic in nature. However, none of the 13 condensed aromatic structures and only 15 of the 67 aromatic formulas identified in the PSOM are found in WSOM, suggesting that pyridine may be selective for certain aromatic and condensed aromatic compounds. We speculate that the aromatic character in these samples is low due to a lack of a strong combustion source. Unfortunately we cannot verify true aromatic content using these methods due to the signal from pyridine in the aromatic region of the ${ }^{1} \mathrm{H}$ NMR spectrum.

Each molecular formula type (e.g., CHO) was plotted on a van Krevelen diagram based on its presence in WSOM, $\mathrm{WIOM}_{\mathrm{pyr}}$, or WIOM $\mathrm{acn}$ (Fig. 4). Phosphorus-containing formulas were omitted from the figure due to their low number frequency and relatively low spectral intensity. Molecular formulas that appear in WSOM and either PSOM or ASOM were removed from the diagrams for PSOM and ASOM
(Fig. 4e-1), so that only the formulas unique to each of the organic solvents (i.e., $\mathrm{WIOM}_{\mathrm{pyr}}$ and $\mathrm{WIOM}_{\mathrm{acn}}$ ) are shown. The lines on each diagram indicate the type of molecular structure (i.e., aliphatic, olefinic, aromatic, and condensed aromatic) based on $\mathrm{AI}_{\text {mod }}$ values. Nearly all of the $\mathrm{CHO}$ formulas in the WSOM (Fig. 4a) have O/C ratios between 0.2 and 0.8 and $\mathrm{H} / \mathrm{C}$ ratios between 0.95 and 2.00. Formulas within this region of the diagram are typical of many types of natural OM samples, and have previously been attributed to lignin (e.g., Sleighter and Hatcher, 2007) and carboxylic-rich alicyclic molecules (CRAM; e.g., Stubbins et al., 2010), or SOA (e.g., Wozniak et al., 2008). While lignin itself is not likely to be highly abundant in the atmosphere, the compounds found in this region of the van Krevelen diagram could be molecularly similar to lignin (i.e., a branched polymer-containing aromatic rings and various oxygenated functional groups) or derivatives of lignin. Several of the compounds $(\sim 33 \%)$ within this region meet the operational definition of CRAM (Hertkorn et al., 2006), and could represent CRAM-like structures (i.e., carboxylated and fused alicyclic rings). A previous study by Wozniak et al. (2008) identified formulas in this region as being consistent with those produced through laboratory aging reactions (e.g., pinene ozonolysis), but FTICR-MS cannot provide direct evidence that the compounds identified in this study are secondary in nature.

The CHON formulas in WSOM (Fig. 4b) are localized to $\mathrm{O} / \mathrm{C}$ ratios between 0.2 and 0.8 and $\mathrm{H} / \mathrm{C}$ ratios between 1.00 and 1.75. The formulas in this region above an $\mathrm{H} / \mathrm{C}$ ratio of 1.50 have previously been attributed to peptides; however, $97 \%$ of these formulas have only one nitrogen and cannot truly be peptides because multiple nitrogen atoms would be required. Additionally, all of these $\mathrm{CHON}$ formulas have an $\mathrm{O} / \mathrm{N}$ ratio of at least 3 , which suggests that the functionality of the nitrogen may be that of a nitrate group $\left(\mathrm{ONO}_{2}\right)$. We also recognize the possibility of reduced nitrogen functional groups (e.g., amines and azo compounds) present in molecules containing other ionizable functional groups (e.g., carboxylic acid), but we are unable to differentiate the two possibilities with this method of analysis. WSOM formulas containing both sulfur and nitrogen (CHONS, Fig. 4c) are predominantly aliphatic with relatively high $\mathrm{O} / \mathrm{C}$ ratios $(>0.5)$. Most $(93 \%)$ of these formulas have sufficient oxygen atoms $(\geq 7)$ to contain at least one nitrate and one sulfate functional group, indicating that many of these formulas could be nitrooxyorganosulfates which have been identified in previous ambient atmospheric samples (e.g., Surratt et al., 2007; LeClair et al., 2012). CHOS formulas are the second most dominant formula type in the WSOM, and these formulas separate into two distinct regions of the van Krevelen diagram (Fig. 4d). One region contains mostly aliphatic and some olefinic formulas with $\mathrm{O} / \mathrm{C}$ ratios greater than 0.25 and $\mathrm{H} / \mathrm{C}$ ratios greater than 1.3. All of the CHOS formulas in this region have $\mathrm{O} / \mathrm{S}$ of at least 4 , suggesting that they are saturated organosulfates or organosulfates with a 
$\mathrm{CHO}$
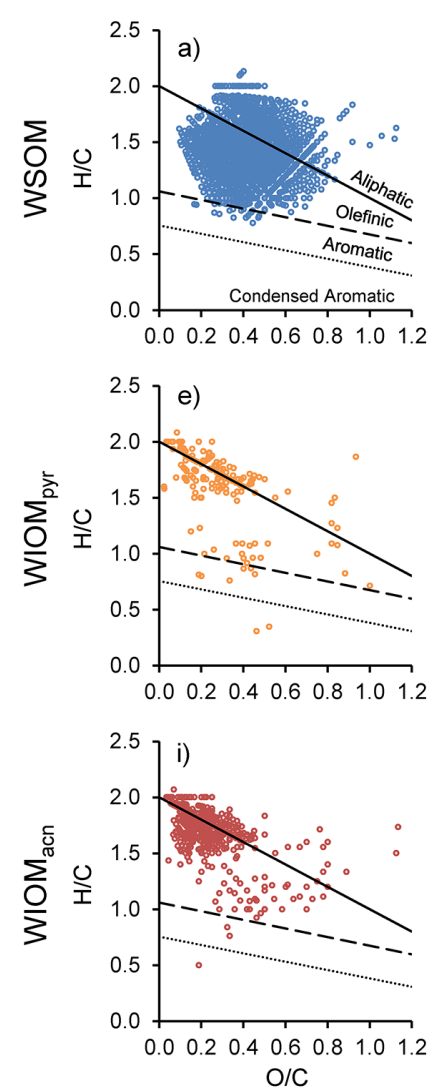

$\mathrm{CHON}$
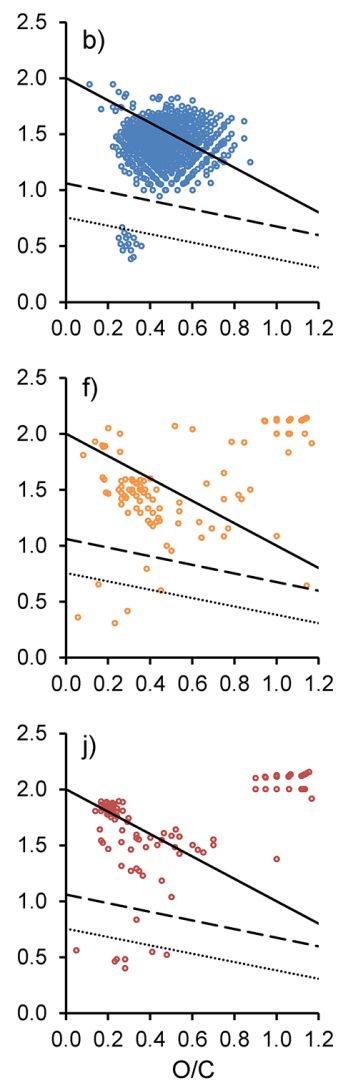

CHONS
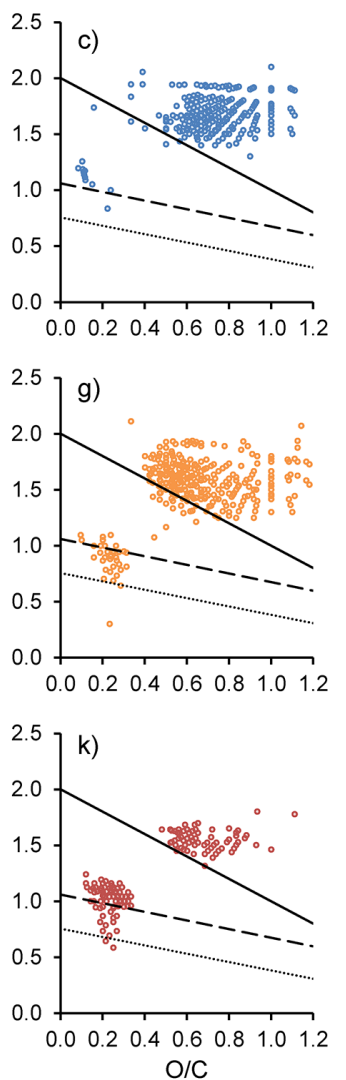

CHOS
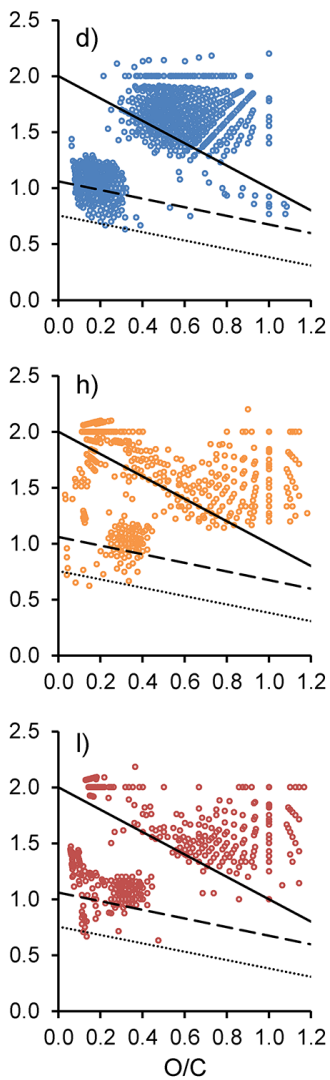

Figure 4. Van Krevelen diagrams for molecular formulas assigned to the (a-d) WSOM, (e-h) WIOM pyr $_{\text {, and (i-l) WIOM }}$ acn extracts. Any formula present in WSOM has been removed from the $\mathrm{WIOM}_{\mathrm{pyr}}$ and $\mathrm{WIOM}_{\mathrm{acn}}$ plots. Each diagram is plotted based on elemental content of each molecular formula (CHO, CHON, CHONS, and CHOS). The labeled regions in (a) WSOM CHO formulas correspond to their aromaticity based on $\mathrm{AI}_{\mathrm{mod}}$ and these regions are consistent for all of the diagrams. Formulas above the solid line are aliphatic, just below the solid line are olefinic, below the dashed line are aromatic, and below the dotted line are condensed aromatic.

few double bonds. The other distinct $\mathrm{CHOS}$ region contains olefinic and aromatic formulas with a low $\mathrm{O} / \mathrm{C}(<0.4)$ and $\mathrm{H} / \mathrm{C}$ ratios less than 1.4. Most (70\%) of these formulas have $\mathrm{O} / \mathrm{S}$ ratios of at least 4 , indicating that they could be aromatic organosulfates or organosulfates with multiple unsaturations. The CHOS formulas that do not have sufficient $\mathrm{O}$ atoms $(\mathrm{O} / \mathrm{S}<4)$ to be organosulfates must contain a reduced sulfur functional group (e.g., sulfonates and thiols). Organic compounds with reduced forms of sulfur, specifically thiaarenes, have been identified in anthropogenic aerosol emissions sources and are known to be toxic (Eastmond et al., 1984; Rogge et al., 1993c). Sulfonates are ubiquitous in detergents and personal care products (Debelius et al., 2008; Lara-Martín et al., 2006), and have been previously identified in atmospheric OM (Altieri et al., 2009). It is important to recognize that atomic ratios do not confirm the presence of organosulfate or organonitrates; however, these structures have been confirmed in other studies of atmospheric $\mathrm{OM}$, and it is reasonable to suggest their presence in these samples. A study by LeClair et al. (2012) of atmospheric
WSOM using FTICR-MS and collision-induced dissociation provides direct evidence for neutral losses of $\mathrm{HNO}_{3}$ from $63 \%$ of detected CHON compounds and $33 \%$ of the detected CHONS compounds, and for neutral losses of $\mathrm{SO}_{3}$ from $85 \%$ of detected CHOS compounds and $42 \%$ of the detected CHONS compounds. Neutral losses of $\mathrm{HNO}_{3}$ and $\mathrm{SO}_{3}$ were interpreted in that study as indicative of organonitrates and organosulfates, respectively. While differences in sample type and instrumentation limit a direct quantitative comparison being made here, their results provide good support for the presence of organonitrates, organosulfates, and nitrooxyorganosulfates in atmospheric WSOM, including these samples. Reduced forms of nitrogen and sulfur are likely also present as evidenced by the formulas with $\mathrm{O} / \mathrm{S}$ less than 4 and the neutral loss evidence in the LeClair et al. (2012) study which indicates reduced forms must make up a portion of the CHON and CHOS compounds.

As stated previously, pyridine is able to dissolve or detect 1030 compounds that water does not (Table 1). The characteristics for all formulas in $\mathrm{WIOM}_{\text {pyr }}$ indicate a lower 
average $\mathrm{O} / \mathrm{C}(0.29)$ than WSOM (0.46), a higher average $\mathrm{H} / \mathrm{C}(1.54)$ than WSOM (1.45), and lower average $\mathrm{AI}_{\text {mod }}$ (0.11) than WSOM $(0.15$, Table 1$)$. The $\mathrm{CHO}$ formulas found in the $\mathrm{WIOM}_{\mathrm{pyr}}$ are plotted in a region of higher $\mathrm{H} / \mathrm{C}$ and lower O/C than those identified in the WSOM (Fig. 4e), implying that they are, on average, more aliphatic and less oxidized than the $\mathrm{CHO}$ compounds found in WSOM. The CHON compounds in $\mathrm{WIOM}_{\mathrm{pyr}}$ show variable $\mathrm{H} / \mathrm{C}$ and $\mathrm{O} / \mathrm{C}$ ratios (Fig. 4f). Most of these compounds are either aliphatic or olefinic, with $\mathrm{O} / \mathrm{N}$ ratios of at least 3 , indicating they may be organonitrates which have been identified previously in atmospheric WSOM (e.g., LeClair et al., 2012). The CHONS formulas make up a large portion of the $\mathrm{WIOM}_{\mathrm{pyr}}$ formulas (30\%) and they are plotted in two distinct regions on the van Krevelen diagram (Fig. 4g). The first region contains the majority of the formulas, and they are largely aliphatic molecules with $\mathrm{O} / \mathrm{C}$ ratios greater than 0.5 and $\mathrm{H} / \mathrm{C}$ ratios greater than 1.25 , and the second region contains mostly aromatic formulas with $\mathrm{O} / \mathrm{C}$ ratios less than 0.4 and $\mathrm{H} / \mathrm{C}$ ratios less than 1.25 . Many $(70 \%)$ of the CHONS formulas contain enough oxygen atoms to contain at least one sulfate and one nitrate functional group, and are potentially nitrooxyorganosulfates. Most (81\%) of the compounds in the high-O/C and high-H/C region contain sufficient oxygen, but only a few $(6 \%)$ of the formulas in the low $\mathrm{O} / \mathrm{C}$ and low $\mathrm{H} / \mathrm{C}$ region have sufficient oxygen to be nitrooxyorganosulfates. The CHONS formulas that do not have sufficient oxygen to form nitrooxyorganosulfates must contain at least one sulfur or nitrogen atom present in a reduced form. CHOS formulas make up the largest fraction (43\%) of $\mathrm{WIOM}_{\mathrm{pyr}}$, and the bulk (96\%) of those formulas are aliphatic or olefinic. Like WSOM, the CHOS formulas in WIOM $_{\text {pyr }}$ are plotted in two distinct regions of the van Krevelen diagram (Fig. 4h). The first region contains mostly aliphatic formulas spanning the entire $\mathrm{O} / \mathrm{C}$ range between 0.03 and 1.2 and have $\mathrm{H} / \mathrm{C}$ ratios greater than 1.2. The second region contains mostly olefinic and aromatic compounds with $\mathrm{O} / \mathrm{C}$ ratios less than 0.5 and $\mathrm{H} / \mathrm{C}$ ratios less than 1.5. The average $\mathrm{O} / \mathrm{C}$ ratio for CHOS compounds in $\mathrm{WIOM}_{\text {pyr }}$ is nearly the same as that of the WSOM $(0.49 \pm 0.31$ and $0.47 \pm 0.23$, respectively), but the standard deviation for $\mathrm{WIOM}_{\mathrm{pyr}}$ is greater. This larger deviation indicates that the $\mathrm{WIOM}_{\mathrm{pyr}}$ CHOS compounds are more diverse than those in WSOM. Most $(80 \%)$ of the CHOS formulas in the WIOM $_{\text {pyr }}$ have $\mathrm{O} / \mathrm{S}$ ratios of at least 4 , suggesting possible organosulfates. Formulas with $\mathrm{O} / \mathrm{S}$ ratios less than 4 indicate the presence of a more reduced form of sulfur within the structure. The average $\mathrm{AI}_{\mathrm{mod}}$ of compounds with more reduced forms of sulfur is much greater than that of compounds with $\mathrm{O} / \mathrm{S}$ sufficient to be organosulfates ( 0.38 and 0.04 , respectively). The major difference between WIOM $_{\text {pyr }}$ and WSOM is the increased detection of aliphatic organosulfates and nitrooxyorganosulfates in the $\mathrm{WIOM}_{\mathrm{pyr}}$, suggesting that pyridine is a more suitable solvent than water for detecting these compounds in aerosol OM using ESI-FTICR-MS.
In spite of having many general molecular formula similarities to WSOM, the characteristics for all formulas in WIOM $_{\text {acn }}(1080)$ indicate a lower average O/C (0.39) than WSOM (0.43), a higher average H/C (1.53) than WSOM (1.45), and an identical average $\mathrm{AI}_{\text {mod }}(0.15)$. These characteristics suggest that the formulas unique to ASOM are less oxygenated and/or have longer carbon chains. This is clearly shown by the many formulas that are plotted on the left side (low O/C) of the van Krevelen diagram for $\mathrm{WIOM}_{\mathrm{acn}}$ (Fig. 3i-1). The average number of carbon atoms per formula is slightly larger at 24 carbon atoms for $\mathrm{WIOM}_{\mathrm{acn}}$ and 22 carbon atoms for WSOM. Both $\mathrm{WIOM}_{\mathrm{acn}}$ and WSOM are dominated by $\mathrm{CHO}$ formulas, but the $\mathrm{CHO}$ compounds in the $\mathrm{WIOM}_{\mathrm{acn}}$ are localized to the upper left corner (low $\mathrm{O} / \mathrm{C}$ and high $\mathrm{H} / \mathrm{C}$ ) of the diagram (Fig. 4i). Essentially all $(99 \%)$ of these formulas are aliphatic or olefinic. There are a small number of CHON formulas (101) found in $\mathrm{WIOM}_{\mathrm{acn}}$, and most of these formulas have higher $\mathrm{H} / \mathrm{C}$ (mean value of 1.66) and are split between a lower $\mathrm{O} / \mathrm{C}(<0.6)$ and a high $\mathrm{O} / \mathrm{C}(>0.8)$. Nearly all $(97 \%)$ of the CHON formulas have an $\mathrm{O} / \mathrm{N}$ ratio greater than 3 , indicating the possibility of these compounds to contain nitrate as part of their structure. The CHONS formulas are also relatively scarce, and they are plotted in two separate areas on the van Krevelen diagram (Fig. 4k). Roughly half of the formulas are plotted below $\mathrm{O} / \mathrm{C}$ ratio of 0.4 and the other half above 0.4 . All of the formulas with $\mathrm{O} / \mathrm{C}>0.4$ have sufficient oxygen atoms (at least 7) to form at least one nitrate and one sulfate group, as is found in nitrooxyorganosulfates, but could still contain reduced $\mathrm{N}$ and $\mathrm{S}$ functional groups. However, only $24 \%$ (17 of 70) of the CHONS formulas in the lower $\mathrm{O} / \mathrm{C}$ region have enough oxygen atoms to form nitrooxyorganosulfates, which indicates the presence of more reduced $\mathrm{N}$ - or S-containing functional groups. Like WSOM, CHOS formulas are the second most abundant molecule type in the $\mathrm{WIOM}_{\mathrm{acn}}$, comprising 387 of the 1080 formulas (36\%). These formulas are split into two regions of the diagram (Fig. 41), where one region is dominated by lower $\mathrm{O} / \mathrm{C}$ and $\mathrm{H} / \mathrm{C}$ ratios and contains mostly olefinic and aromatic compounds, and the other region is predominantly aliphatic compounds covering the full range of $\mathrm{O} / \mathrm{C}$ ratios. The majority $(76 \%)$ of all of the CHOS formulas have sufficient oxygen to form organosulfates $(\mathrm{O} / \mathrm{S} \geq 4)$. All of the formulas in the higher $\mathrm{H} / \mathrm{C}$ and aliphatic region contain sufficient oxygen to form organosulfates, but more than half $(55 \%)$ of the formulas in the low $\mathrm{H} / \mathrm{C}$ and low $\mathrm{O} / \mathrm{C}$ region have $\mathrm{O} / \mathrm{S}$ ratios less than 4 . These formulas in the low $\mathrm{O} / \mathrm{C}$ and low $\mathrm{H} / \mathrm{C}$ region have multiple unsaturations and more reduced forms of sulfur in their structure. The major differences between $\mathrm{WIOM}_{\mathrm{acn}}$ and WSOM are in the high $\mathrm{H} / \mathrm{C}$ and low $\mathrm{O} / \mathrm{C}$ region, suggesting that acetonitrile is a more suitable solvent than water for detecting less polar aerosol OM compounds (i.e., fewer oxygen and heteroatoms and/or larger carbon chains) by ESI-FTICRMS. 
The WIOM compounds have chemical characteristics distinct from those in WSOM. Both organic solvents extracted compounds that were more aliphatic in nature than those found in the WSOM, as indicated by the lower $\mathrm{O} / \mathrm{C}$ ratios and longer carbon chain lengths (for ASOM) of the CHO formulas. Previous work has shown that aliphatic components make up a small fraction of aerosol OC, implying that they are, as expected, largely water-insoluble (Wozniak et al., 2012b). Radiocarbon signatures indicate that the waterinsoluble components are mostly fossil-derived (Wozniak et al., 2012b), but can also come from contemporary plant material (Rogge et al., 1993b). The aliphatic and olefinic hydrocarbon material that is released during fossil fuel combustion can be functionalized through various atmospheric oxidation reactions, thus increasing its polarity and water solubility.

Nearly $75 \%$ of the formulas unique to PSOM include sulfur as part of the molecular formula, indicating a potential selectivity for organosulfates and nitrooxyorganosulfates. This selectivity may be due, in part, to the increased efficiency of aliphatic species (over unsaturated species) to undergo reactions with $\mathrm{SO}_{\mathrm{x}}$, and that pyridine may actually be selective for the aliphatic portion rather than the actual sulfate functional group. Sulfur species, especially $\mathrm{SO}_{\mathrm{x}}$, are well known to play important roles in atmospheric aging reactions. Organosulfates are formed in the atmosphere through the acid-catalyzed ring-opening reaction of epoxides in the presence of acidic sulfate seed aerosols (Minerath and Elrod, 2009), and these organosulfates can undergo nighttime nitrate radical oxidation and photooxidation to form nitrooxyorganosulfates (Surratt et al., 2008). These compounds have been identified in ambient atmospheric OM (e.g., Altieri et al., 2012; Mazzoleni et al., 2012; Mitra et al., 2013; Reemtsma et al., 2006; Schmitt-Kopplin et al., 2010; Wozniak et al., 2008). Sulfate is emitted from numerous anthropogenic and biogenic sources and is ubiquitous in the atmosphere. The aerosol OM at this sampling site was in proximity to a known $\mathrm{SO}_{\mathrm{x}}$ emission source (coal-fired power plant), providing ample opportunity for atmospheric aging reactions with sulfate to occur and form the observed organosulfate compounds. Organosulfates are very polar in nature, which may increase the ability of aerosol OM to act as cloud condensation nuclei and therefore have an indirect radiative effect (Hallquist et al., 2009).

\section{Conclusions}

Pyridine and acetonitrile are suitable solvents for analyzing organic aerosols using ESI-FTICR-MS and identify a molecularly unique portion of aerosol OM when compared to the water-soluble fraction. While the water-soluble fraction is of paramount importance due to the implications those compounds have on environmental processes, such as cloud condensation nuclei formation and mobility in watersheds, analysis of only the WSOM omits a large portion of OM (as much as $90 \%$ ). The PSOM and ASOM fractions are expected to be more lipophilic and are likely to be more interactive with biological tissues in the environment. Acetonitrile was able to analyze several unique water-insoluble molecular formulas; however, the elemental distributions and formula types (e.g., aliphatic) of these compounds were very similar to those of WSOM. Pyridine elucidated a molecularly unique, and therefore complementary, set of chemical formulas compared to those in either ASOM or WSOM. PSOM has a stronger preference for extracting or analyzing aliphatic sulfur-containing formulas, which are important aerosol components due to their abundance and hygroscopicity, which allows them to act as cloud condensation nuclei and impact climate via the indirect effect. Because WIOM has been found to contain the majority of fossil-fuel-derived OM, analysis of the WIOM, such as OM found in ASOM and PSOM, provides clues to the molecular composition of the fossil material present in aerosols emitted from anthropogenic sources and therefore insights into its potential fates in, and impacts on, the environment.

\section{The Supplement related to this article is available online at doi:10.5194/acp-14-10299-2014-supplement.}

Acknowledgements. The work presented in this manuscript was funded by the Frank Batten endowment to P. G. Hatcher. A. S. Willoughby was funded by the US EPA STAR graduate fellowship program, Grant FP 91736001. The EPA has not officially endorsed this publication and the views expressed herein may not reflect the views of the EPA. The authors acknowledge assistance from the ODU COSMIC facility for FTICR-MS and NMR analyses. We thank Rachel Sleighter for useful discussions about the data.

Edited by: S. A. Nizkorodov

\section{References}

Alfarra, M. R., Paulsen, D., Gysel, M., Garforth, A. A., Dommen, J., Prévôt, A. S. H., Worsnop, D. R., Baltensperger, U., and Coe, H.: A mass spectrometric study of secondary organic aerosols formed from the photooxidation of anthropogenic and biogenic precursors in a reaction chamber, Atmos. Chem. Phys., 6, 52795293, doi:10.5194/acp-6-5279-2006, 2006.

Altieri, K. E., Hastings, M. G., Peters, A. J., and Sigman, D. M.: Molecular characterization of water soluble organic nitrogen in marine rainwater by ultrahigh resolution electrospray ionization mass spectrometry, Atmos. Chem. Phys., 12, 3557-3571, doi:10.5194/acp-12-3557-2012, 2012.

Altieri, K. E., Turpin, B. J., and Seitzinger, S. P.: Oligomers, organosulfates, and nitrooxy organosulfates in rainwater identified by ultrahigh resolution electrospray ionization FTICR mass spectrometry, Atmos. Chem. Phys., 9, 2533-2542, doi:10.5194/acp-9-2533-2009, 2009. 
Andreae, M. O. and Crutzen, P. J.: Atmospheric aerosols: Biogeochemical sources and role in atmospheric chemistry, Science, 276, 1052-1058, 1997.

Andreae, M. O. and Gelencsér, A.: Black carbon or brown carbon? The nature of light-absorbing carbonaceous aerosols, Atmos. Chem. Phys., 6, 3131-3148, doi:10.5194/acp-6-3131-2006, 2006.

Bateman, A. P., Nizkorodov, S. A., Laskin, J., and Laskin, A.: Highresolution electrospray ionization mass spectrometry analysis of water-soluble organic aerosols collected with a particle into liquid sampler, Anal. Chem., 82, 8010-8016, 2010.

Bateman, A. P., Walser, M. L., Desyaterik, Y., Laskin, J., Laskin, A., and Nizkorodov, S. A.: The effect of solvent on the analysis of secondary organic aerosol using electrospray ionization mass spectrometry, Environ. Sci. Technol., 42, 7341-7346, 2008.

Bond, T. C., Doherty, S. J., Fahey, D. W., Forster, P. M., Berntsen, T., DeAngelo, B. J., Flanner, M. G., Ghan, S., Kärcher, B., Koch, D., Kinne, S., Kondo, Y., Quinn, P. K., Sarofim, M. C., Schultz, M. G., Schultz, M., Venkataraman, C., Zhang, H., Zhang, S., Bellouin, N., Guttikunda, S. K., Hopke, P. K., Jacobson, M. Z., Kaiser, J. W., Klimont, Z., Lohmann, U., Schwarz, J. P., Shindell, D., Storelvmo, T., Warren, S. G., and Zender, C. S.: Bounding the role of black carbon in the climate system: A scientific assessment, J. Geophys. Res.-Atmos., 118, 1-173, 2013.

Booth, B. B. B., Dunstone, N. J., Halloran, P. R., Andrews, T., and Bellouin, N.: Aerosols implicated as a prime driver of twentiethcentury North Atlantic climate variability, Nature, 484, 228-232, 2012.

Crutzen, P. J. and Andreae, M. O.: Biomass burning in the tropics: Impact on atmospheric chemistry and biogeochemical cycles, Science, 250, 1669-1678, 1990.

Debelius, B., Forja, J. M., Del Valls, A., and Lubián, L. M.: Effect of linear alkylbenzene sulfonate (LAS) and atrazine on marine microalgae, Mar. Pollut. Bull., 57, 559-568, 2008.

Decesari, S., Mircea, M., Cavalli, F., Fuzzi, S., Moretti, F., Tagliavini, E., and Facchini, M. C.: Source attribution of water-soluble organic aerosol by nuclear magnetic resonance spectroscopy, Environ. Sci. Technol., 41, 2479-2484, 2007.

Dittmar, T., Koch, B., Hertkorn, N., and Kattner, G.: A simple and efficient method for the solid-phase extraction of dissolved organic matter (SPE-DOM) from seawater, Limnol. OceanogrMeth., 6, 230-235, 2008.

Eastmond, D. A., Booth, G. M., and Lee, M. L.: Toxicity, accumulation, and elimination of polycyclic aromatic sulfur heterocycles in Daphnia magna, Arch. Environ. Con. Tox., 13, 105-111, 1984.

Hallquist, M., Wenger, J. C., Baltensperger, U., Rudich, Y., Simpson, D., Claeys, M., Dommen, J., Donahue, N. M., George, C., Goldstein, A. H., Hamilton, J. F., Herrmann, H., Hoffmann, T., Iinuma, Y., Jang, M., Jenkin, M. E., Jimenez, J. L., Kiendler-Scharr, A., Maenhaut, W., McFiggans, G., Mentel, Th. F., Monod, A., Prévôt, A. S. H., Seinfeld, J. H., Surratt, J. D., Szmigielski, R., and Wildt, J.: The formation, properties and impact of secondary organic aerosol: current and emerging issues, Atmos. Chem. Phys., 9, 5155-5236, doi:10.5194/acp-9-51552009, 2009.

Heaton, K. J., Sleighter, R. L., Hatcher, P. G., Hall IV, W. A., and Johnston, M. V.: Composition domains in monoterpene sec- ondary organic aerosol, Environ. Sci. Technol., 43, 6950-6955, 2009.

Hertkorn, N., Benner, R., Frommberger, M., Schmitt-Kopplin, P., Witt, M., Kaiser, K., Kettrup, A., and Hedges, J. I.: Characterization of a major refractory component of marine dissolved organic matter, Geochim. Cosmochim. Ac., 70, 2990-3010, 2006.

Hockaday, W. C., Grannas, A. M., Kim, S., and Hatcher, P. G.: Direct molecular evidence for the degradation and mobility of black carbon in soils from ultrahigh-resolution mass spectral analysis of dissolved organic matter from a fire-impacted forest soil, Org. Geochem., 37, 501-510, 2006.

Jacobson, M. Z.: Physically-based treatment of elemental carbon optics: Implications for global direct forcing of aerosols, Geophys. Res. Lett., 27, 217-220, 2000.

Jimenez, J. L., Canagaratna, M. R., Donahue, N. M., Prévôt, A. S. H., Zhang, Q., Kroll, J. H., DeCarlo, P. F., Allan, J. D., Coe, H., Ng, N. L., Aiken, A. C., Docherty, K. S., Ulbrich, I. M., Grieshop, A. P., Robinson, A. L., Duplissy, J., Smith, J. D., Wilson, K. R., Lanz, V. A., Hueglin, C., Sun, Y. L., Tian, J., Laaksonen, A., Raatikainen, T., Rautiainen, J., Vaattovaara, P., Ehn, M., Kulmala, M., Tomlinson, J. M., Collins, D. R., Cubison, M. J., Dunlea, E. J., Huffman, J. A., Onasch, T. B., Alfarra, M. R., Williams, P. I., Bower, K., Kondo, Y., Schneider, J., Drewnick, F., Borrmann, S., Weimer, S., Demerjian, K., Salcedo, D., Cottrell, L., Griffin, R., Takami, A., Miyoshi, T., Hatakeyama, S., Shimono, A., Sun, J. Y., Zhang, Y. M., Dzepina, K., Kimmel, J. R., Sueper, D., Jayne, J. T., Herndon, S. C., Trimborn, A. M., Williams, L. R., Wood, E. C., Middlebrook, A. M., Kolb, C. E., Baltensperger, U., and Worsnop, D. R.: Evolution of organic aerosols in the atmosphere, Science, 326, 1525-1529, 2009.

Kamga, A. W., Behar, F., and Hatcher, P. G.: Quantitative analysis of long chain fatty acids present in a Type I kerogen using electrospray ionization Fourier transform ion cyclotron resonance mass spectrometry: Compared with $\mathrm{BF}_{3} / \mathrm{MeOH}$ methylation/GC-FID, J. Am. Soc. Mass Spectrom., 25, 880-890, 2014.

Kanakidou, M., Seinfeld, J. H., Pandis, S. N., Barnes, I., Dentener, F. J., Facchini, M. C., Van Dingenen, R., Ervens, B., Nenes, A., Nielsen, C. J., Swietlicki, E., Putaud, J. P., Balkanski, Y., Fuzzi, S., Horth, J., Moortgat, G. K., Winterhalter, R., Myhre, C. E. L., Tsigaridis, K., Vignati, E., Stephanou, E. G., and Wilson, J.: Organic aerosol and global climate modelling: a review, Atmos. Chem. Phys., 5, 1053-1123, doi:10.5194/acp-5-1053-2005, 2005.

Kendrick, E.: A mass scale based on $\mathrm{CH}_{2}=140000$ for high resolution mass spectrometry of organic compounds, Anal. Chem., 35, 2146-2154, 1963.

Kleefeld, S., Hoffer, A., Krivacsy, Z., and Jennings, S. G.: Importance of organic and black carbon in atmospheric aerosols at Mace Head, on the West Coast of Ireland $\left(53^{\circ} 19^{\prime} \mathrm{N}, 9^{\circ} 54^{\prime} \mathrm{W}\right)$, Atmos. Environ., 36, 4479-4490, 2002.

Koch, B. P. and Dittmar, T.: From mass to structure: an aromaticity index for high-resolution mass data of natural organic matter, Rapid Commun. Mass Sp., 20, 926-932, 2006.

Lara-Martín, P. A., Gómez-Parra, A., and González-Mazo, E.: Development of a method for the simultaneous analysis of anionic and non-ionic surfactants and their carboxylated metabolites in environmental samples by mixed-mode liquid chromatographymass spectrometry, J. Chromatogr. A, 1137, 188-197, 2006. 
Laskin, J., Laskin, A., Roach, P. J., Slysz, G. W., Anderson, G. A., Nizkorodov, S. A., Bones, D. L., and Nguyen, L. Q.: Highresolution desorption electrospray ionization mass spectrometry for chemical characterization of organic aerosols, Anal. Chem., 82, 2048-2058, 2010.

LeClair, J. P., Collett, J. L., and Mazzoleni, L. R.: Fragmentation analysis of water-soluble atmospheric organic matter using ultrahigh-resolution FT-ICR mass spectrometry, Environ. Sci. Technol., 46, 4312-4322, 2012.

Lin, P., Rincon, A. G., Kalberer, M., and Yu, J. Z.: Elemental composition of HULIS in the Pearl River Delta Region, China: Results inferred from positive and negative electrospray high resolution mass spectrometric data, Environ. Sci. Technol., 46, 7454 $7462,2012$.

Mayol-Bracero, O. L., Guyon, P., Graham, B., Roberts, G., Andreae, M. O., Decesari, S., Facchini, M. C., Fuzzi, S., and Artaxo, P.: Water-soluble organic compounds in biomass burning aerosols over Amazonia 2. Apportionment of the chemical composition and importance of the polyacidic fraction, J. Geophys. Res., 107, 8091, doi:10.1029/2001JD000522, 2002.

Mazzoleni, L. R., Ehrmann, B. M., Shen, X., Marshall, A. G., and Collett Jr, J. L.: Water-soluble atmospheric organic matter in fog: exact masses and chemical formula identification by ultrahighresolution Fourier transform ion cyclotron resonance mass spectrometry, Environ. Sci. Technol., 44, 3690-3697, 2010.

Mazzoleni, L. R., Saranjampour, P., Dalbec, M. M., Samburova, V., Hallar, A. G., Zielinska, B., Lowenthal, D. H., and Kohl, S.: Identification of water-soluble organic carbon in non-urban aerosols using ultrahigh-resolution FT-ICR mass spectrometry: organic anions, Environ. Chem., 9, 285-297, 2012.

McKee, G. A. and Hatcher, P. G.: Alkyl amides in two organic-rich anoxic sediments: A possible new abiotic route for $\mathrm{N}$ sequestration, Geochim. Cosmochim. Ac., 74, 6436-6450, 2010.

Minerath, E. C. and Elrod, M. J.: Assessing the potential for diol and hydroxy sulfate ester formation from the reaction of epoxides in tropospheric aerosols, Environ. Sci. Technol., 43, 1386-1392, 2009.

Mitra, S., Wozniak, A. S., Miller, R., Hatcher, P. G., Buonassissi, C., and Brown, M.: Multiproxy probing of rainwater dissolved organic matter (DOM) composition in coastal storms as a function of trajectory, Mar. Chem., 154, 67-76, 2013.

Moretti, F., Tagliavini, E., Decesari, S., Facchini, M. C., Rinaldi, M., and Fuzzi, S.: NMR determination of total carbonyls and carboxyls: a tool for tracing the evolution of atmospheric oxidized organic aerosols, Environ. Sci. Technol., 42, 4844-4849, 2008.

Ramanathan, V., Crutzen, P. J., Kiehl, J. T., and Rosenfeld, D.: Aerosols, climate, and the hydrological cycle, Science, 294, 2119-2124, 2001.

Reemtsma, T., These, A., Venkatachari, P., Xia, X., Hopke, P. K., Springer, A., and Linscheids, M.: Identification of fulvic acids and sulfated and nitrated analogues in atmospheric aerosol by electrospray ionization Fourier transform ion cyclotron resonance mass spectrometry, Anal. Chem., 78, 8299-8304, 2006.

Reinhardt, A., Emmenegger, C., Gerrits, B., Panse, C., Dommen, J., Baltensperger, U., Zenobi, R., and Kalberer, M.: Ultrahigh mass resolution and accurate mass measurements as a tool to characterize oligomers in secondary organic aerosols, Anal. Chem., 79, 4074-4082, 2007.
Robertson, J. and O'Reilly, E. P.: Electronic and atomic structure of amorphous carbon, Phys. Rev. B, 35, 2946-2957, 1987.

Rogge, W. F., Hildemann, L. M., Mazurek, M. A., Cass, G. R., and Simoneit, B. R. T.: Sources of fine organic aerosol. 2. Noncatalyst and catalyst-equipped automobiles and heavy-duty diesel trucks, Environ. Sci. Technol., 27, 636-651, 1993a.

Rogge, W. F., Hildemann, L. M., Mazurek, M. A., Cass, G. R., and Simoneit, B. R. T.: Sources of fine organic aerosol. 4. Particulate abrasion products from leaf surfaces of urban plants, Environ. Sci. Technol., 27, 2700-2711, 1993b.

Rogge, W. F., Hildemann, L. M., Mazurek, M. A., Cass, G. R., and Simoneit, B. R. T.: Sources of fine organic aerosol. 5. Natural gas home appliances, Environ. Sci. Technol., 27, 2736-2744, 1993c.

Salmon, E., Behar, F., and Hatcher, P. G.: Molecular characterization of Type I kerogen from the Green River Formation using advanced NMR techniques in combination with electrospray ionization/ultrahigh resolution mass spectrometry, Org. Geochem., 42, 301-315, 2011.

Sanders, J. K. and Hunter, B. K.: Modern NMR spectroscopy: a guide for chemists, Oxford University Press Inc., New York, NY, 1993.

Schmitt-Kopplin, P., Gelencser, A., Dabek-Zlotorzynska, E., Kiss, G., Hertkorn, N., Harir, M., Hong, Y., and Gebefugi, I.: Analysis of the unresolved organic fraction in atmospheric aerosols with ultrahigh-resolution mass spectrometry and nuclear magnetic resonance spectroscopy: Organosulfates as photochemical smog constituents, Anal. Chem., 82, 8017-8026, 2010.

Shakya, K. M., Place, P. F., Griffin, R. J., and Talbot, R. W.: Carbonaceous content and water-soluble organic functionality of atmospheric aerosols at a semi-rural New England location, J. Geophys. Res.-Atmos., 117, D03301, doi:10.1029/2011JD016113, 2012.

Sleighter, R. L. and Hatcher, P. G.: The application of electrospray ionization coupled to ultrahigh resolution mass spectrometry for the molecular characterization of natural organic matter, J. Mass Spectrom., 42, 559-574, 2007.

Sleighter, R. L., McKee, G. A., Liu, Z., and Hatcher, P. G.: Naturally present fatty acids as internal calibrants for Fourier transform mass spectra of dissolved organic matter, Limnol. Oceanogr.Meth., 6, 246-253, 2008.

Sleighter, R. L., Chen, H., Wozniak, A. S., Willoughby, A. S., Caricasole, P., and Hatcher, P. G.: Establishing a measure of reproducibility of ultrahigh-resolution mass spectra for complex mixtures of natural organic matter, Anal. Chem., 84, 9184-9191, 2012.

Stubbins, A., Spencer, R. G. M., Chen, H., Hatcher, P. G., Mopper, K., Hernes, P. J., Mwamba, V. L., Mangangu, A. M., Wabakanghanzi, J. N., and Six, J.: Illuminated darkness: Molecular signatures of Congo River dissolved organic matter and its photochemical alteration as revealed by ultrahigh precision mass spectrometry, Limnol. Oceanogr., 55, 1467-1477, 2010.

Stubbins, A., Hood, E., Raymond, P. A., Aiken, G. R., Sleighter, R. L., Hernes, P. J., Butman, D., Hatcher, P. G., Striegl, R. G., and Schuster, P.: Anthropogenic aerosols as a source of ancient dissolved organic matter in glaciers, Nat. Geosci., 5, 198-201, 2012.

Sullivan, A. P., Weber, R. J., Clements, A. L., Turner, J. R., Bae, M. S., and Schauer, J. J.: A method for on-line measurement of water-soluble organic carbon in ambient aerosol particles: 
Results from an urban site, Geophys. Res. Lett., 31, L13105, doi:10.1029/2004GL019681, 2004.

Surratt, J. D., Kroll, J. H., Kleindienst, T. E., Edney, E. O., Claeys, M., Sorooshian, A., Ng, N. L., Offenberg, J. H., Lewandowski, M., and Jaoui, M.: Evidence for organosulfates in secondary organic aerosol, Environ. Sci. Technol., 41, 517-527, 2007.

Surratt, J. D., Gómez-González, Y., Chan, A. W. H., Vermeylen, R., Shahgholi, M., Kleindienst, T. E., Edney, E. O., Offenberg, J. H., Lewandowski, M., and Jaoui, M.: Organosulfate formation in biogenic secondary organic aerosol, J. Phys. Chem. A, 112, 8345-8378, 2008.

Szidat, S., Jenk, T. M., Gaggeler, H. W., Synal, H. A., Fisseha, R., Baltensperger, U., Kalberer, K., Samburova, V., Wacker, L., and Saurer, M.: Source apportionment of aerosols by ${ }^{14} \mathrm{C}$ measurements in different carbonaceous particle fractions, Radiocarbon, 46, 475-484, 2004.

Wozniak, A. S., Bauer, J. E., Sleighter, R. L., Dickhut, R. M., and Hatcher, P. G.: Technical Note: Molecular characterization of aerosol-derived water soluble organic carbon using ultrahigh resolution electrospray ionization Fourier transform ion cyclotron resonance mass spectrometry, Atmos. Chem. Phys., 8, 50995111, doi:10.5194/acp-8-5099-2008, 2008.
Wozniak, A. S., Bauer, J. E., and Dickhut, R. M.: Characteristics of water-soluble organic carbon associated with aerosol particles in the eastern United States, Atmos. Environ., 46, 181-188, 2012a.

Wozniak, A. S., Bauer, J. E., Dickhut, R. M., Xu, L., and McNichol, A. P.: Isotopic characterization of aerosol organic carbon components over the eastern United States, J. Geophys. Res., 117, D13303, doi:10.1029/2011JD017153, 2012b.

Wu, Z., Jernström, S., Hughey, C. A., Rodgers, R. P., and Marshall, A. G.: Resolution of 10000 compositionally distinct components in polar coal extracts by negative-ion electrospray ionization Fourier transform ion cyclotron resonance mass spectrometry, Energ. Fuel, 17, 946-953, 2003.

Zappoli, S., Andracchio, A., Fuzzi, S., Facchini, M. C., Gelencser, A., Kiss, G., Krivacsy, Z., Molnar, A., Meszaros, E., Hansson, H. C., Rosman, K., and Zebühr, Y.: Inorganic, organic and macromolecular components of fine aerosol in different areas of Europe in relation to their water solubility, Atmos. Environ., 33, 2733$2743,1999$. 